\title{
When forms meet genes: revision of the scleractinian genera Micromussa and Homophyllia (Lobophylliidae) with a description of two new species and one new genus
}

Roberto Arrigoni ${ }^{1,2,{ }^{*}}$ Francesca Benzoni2, 3, 15, ${ }^{*}$ Danwei Huang ${ }^{4,5}$, Hironobu Fukami ${ }^{6}$, Chaolun Allen Chen $^{7,8}$, Michael L. Berumen ${ }^{1}$, Mia Hoogenboom ${ }^{9}$, Damian P. Thomson ${ }^{10}$, Bert W. Hoeksema ${ }^{11}$, Ann F. Budd ${ }^{5}$, Yuna Zayasu ${ }^{12}$, Tullia I. Terraneo ${ }^{1}$, Yuko F. Kitano ${ }^{13}$, Andrew H. Baird ${ }^{14}$

${ }^{1}$ Red Sea Research Center, Division of Biological and Environmental Science and Engineering, King Abdullah University of Science and Technology, Thuwal 23955-6900, Saudi Arabia

${ }^{2}$ Department of Biotechnologies and Biosciences, University of Milano - Bicocca, Piazza della Scienza 2, 20126, Milan, Italy

${ }^{3}$ UMR ENTROPIE (IRD, Université de La Réunion, CNRS), Laboratoire d'excellence-CORAIL, centre IRD de Nouméa, New Caledonia, 101 Promenade Roger Laroque, BP A5, 98848 Noumea Cedex, New Caledonia

${ }^{4}$ Department of Biological Sciences and Tropical Marine Science Institute, National University of Singapore, Singapore 117543, Singapore

${ }^{5}$ Department of Earth and Environmental Sciences, University of Iowa, Iowa City, IA, 52242, USA

${ }^{6}$ Faculty of Agriculture, University of Miyazaki, 1-1 Gakuenkibanadai-Nishi, Miyazaki, 889-2192, Japan

${ }^{7}$ Biodiversity Research Centre, Academia Sinica, Nangang, Taipei 115, Taiwan

${ }^{8}$ Institute of Oceanography, National Taiwan University, Taipei 106, Taiwan

${ }^{9}$ College of Marine and Environmental Science and ARC Centre of Excellence for Coral Reef Studies, James Cook University, Townsville, QLD 4811, Australia

${ }^{10}$ CSIRO Oceans and Atmosphere, Floreat, WA 6014, Australia

${ }^{11}$ Naturalis Biodiversity Center, PO Box 9517, 2300 RA Leiden, The Netherlands

${ }^{12}$ Marine Genomics Unit, Okinawa Institute of Science and Technology Graduate University, 1919-1 Tancha, Onna-son, Okinawa, 904-0495, Japan

${ }^{13}$ Organization for Promotion of Tenure Track, University of Miyazaki, 1-1 Gakuenkibanadai-Nishi, Miyazaki, 889-2192, Japan

${ }^{14}$ ARC Centre of Excellence for Coral Reef Studies, James Cook University, Townsville, QLD 4811, Australia

${ }^{15}$ E-mail:francesca.benzoni@unimib.it

* These authors contributed equally to this work

Key words: coral, evolution, phylogeny, systematics, taxonomy

\begin{abstract}
The scleractinian family Lobophylliidae is undergoing a major taxonomic revision thanks to the combination of molecular and morphological data. In this study, we investigate the evolutionary relationships and the macro- and micromorphology of six nominal coral species belonging to two of the nine molecular clades of the Lobophylliidae, clades A and B, and of Symphyllia wilsoni, a lobophylliid species analyzed from a molecular point of view for the first time. Sequence data from mitochondrial DNA (COI and the intergenic spacer between COI and 1-rRNA), and nuclear DNA (histone H3 and ITS region) are used to generate robust molecular phylogenies and a median-joining haplotype network. Molecular results are strongly in agreement with detailed observations of gross- and fine-scale morphology of skeletons, leading to the formal revision of the genera Micromussa and Homophyllia and the description of two newly discovered zooxanthellate shallow-water species, Micromussa
\end{abstract}

pacifica sp. nov. Benzoni \& Arrigoni and Micromussa indiana sp. nov. Benzoni \& Arrigoni, and a new genus, Australophyllia gen. nov. Benzoni \& Arrigoni. In particular, Acanthastrea lordhowensis and Montastraea multipunctata are moved into $\mathrm{Mi}$ cromussa, A. hillae is synonymized with A. bowerbanki and is transferred to Homophyllia, and a revised diagnosis for both genera is provided. Micromussa pacifica sp. nov. is described from the Gambier Islands with its distribution spanning New Caledonia and eastern Australia. Despite a superficial resemblance with Homophyllia australis, it has distinctive macroand micromorphological septal features. Micromussa indiana sp. nov., previously identified as M. amakusensis, is here described from the Gulf of Aden and the southern Red Sea as a distinct species that is genetically separated from M. amakuse$n$ sis and is morphologically distinct from the latter due to its smaller corallite size and lower number of septa. Finally, molecular trees show that $S$. wilsoni is closely related, but molecularly separated from clades A and B, and, also based on a unique 
combination of corallite and sub-corallite characters, the species is moved into Australophyllia gen. nov. These findings confirm the need for using both genetic and morphological datasets for the ongoing taxonomic revision of scleractinian corals.

\section{Contents}

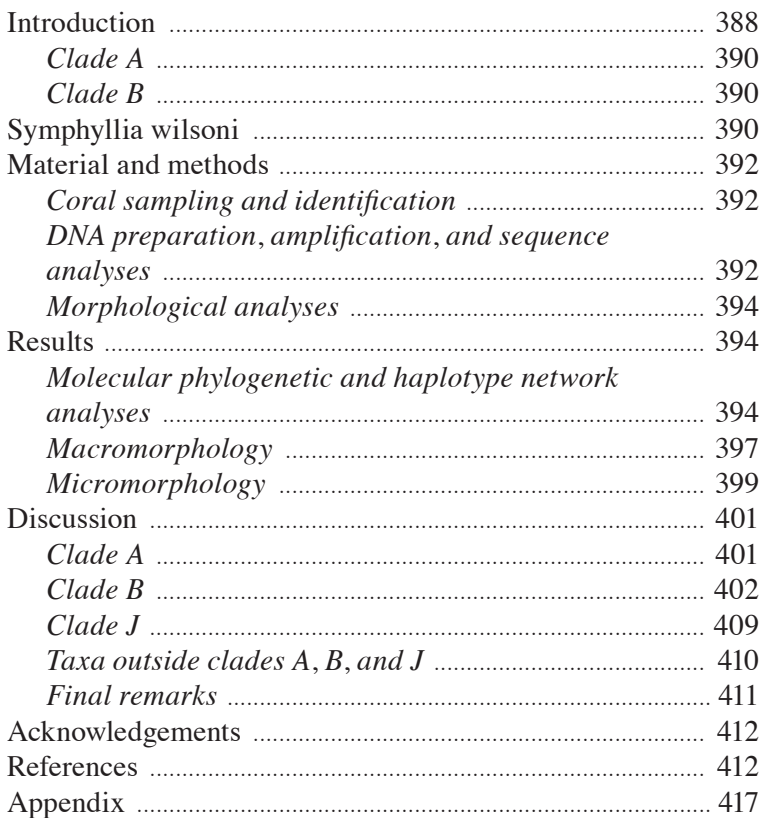

\section{Introduction}

In the last decade the increasing use of molecular tools and novel morphological analyses have shed new light on the evolution and systematics of scleractinian corals (Stolarski, 2003; Fukami et al., 2004a, 2008; Wallace et al., 2007; Budd and Stolarski, 2009, 2011; Gittenberger et al., 2011; Stolarski et al., 2011; Huang et al., 2011; Kitano et al., 2014; Kitahara et al., 2016). The integration of genetics and morphology has provided new hypotheses about the evolutionary history of scleractinian corals, and has led to a revolution in their taxonomy at all ranks (Stolarski and Janiszewska, 2001; Budd et al., 2010, 2012; Stolarski et al., 2011; Benzoni et al., 2012a, b; Kitahara et al., 2012b; Huang et al., 2014a).

The family Lobophylliidae Dai \& Horng, 2009 is an ecologically important group in tropical Indo-Pacific coral reefs (Veron and Pichon, 1980; Scheer and Pillai, 1983; Veron, 1993, 2000). Based on morphological characters, it currently comprises 12 extant genera and 52 zooxanthellate species and is widely distributed from the Red Sea and eastern Africa to French Polynesia (Veron, 2000; Dai and Horng, 2009; Budd et al., 2012; Benzoni, 2013; Hoogenboom et al., 2015). To date, based on mitochondrial and nuclear phylogenies, this taxon corresponds to a monophyletic lineage consisting of nine main genus-level molecular clades, clades A to I sensu Arrigoni et al. (2014a), which are mostly in disagreement with the taxonomy of lobophylliids that until recently has been based solely on macromorphology (Arrigoni et al., 2012, 2014a). Indeed, all polytypic genera described in Veron (2000) analyzed so far, i.e. Acanthastrea Milne Edwards \& Haime, 1848, Echinophyllia Klunzinger, 1879, Lobophyllia de Blainville, 1830, Micromussa Veron, 2000, Oxypora Saville Kent, 1871, and Symphyllia Milne Edwards \& Haime, 1848, are not monophyletic (Arrigoni et al., 2014a). Furthermore, the phylogenetic position and taxonomy of two monospecific genera, Echinomorpha Veron, 2000 and Homophyllia Brüggemann, 1877, were still uncertain (Budd et al., 2012) because they have previously not been investigated at a molecular level, while the monotypic genus Moseleya has already been molecularly characterized (Huang et al., 2011).

Recent work has integrated molecular findings with novel macro- and micromorphological skeleton data, leading to the identification of a new set of informative characters useful for revising the family taxonomy and systematics (Budd and Stolarski, 2009; Budd et al., 2012; Arrigoni et al., 2014b, 2015). In particular, micromorphological characters such as the height, spacing, and shape of septal teeth; the distribution and shape of granules on septal faces; and the structure of the area between teeth (Budd and Stolarski, 2009, 2011) are now known to be informative and diagnostic for the Lobophylliidae (Budd and Stolarski, 2009; Budd et al., 2012; Arrigoni et al., 2014b, 2015) as in other coral families (Hoeksema, 1989; Benzoni et al., 2007, 2012a; Gittenberger et al., 2011; Budd and Stolarski, 2011; Janiszewska et al., 2011, 2013, 2015; Budd et al., 2012; Schmidt-Roach et al., 2014; Huang et al., 2014a, b). Therefore, the family Lobophylliidae is currently undergoing a revision that started with the phylogenetic re-classification of the genera Australomussa Veron, 1985, Parascolymia Wells, 1964, and Sclerophyllia Klunzinger, 1879, as a result of the aforementioned integrated morpho-molecular approach (Arrigoni et al., 2014b, 2015).

In a recent study, unexpected genetic affinities were found between the Lobophylliidae species included in the sister clades A and B sensu Arrigoni et al. (2014a). 

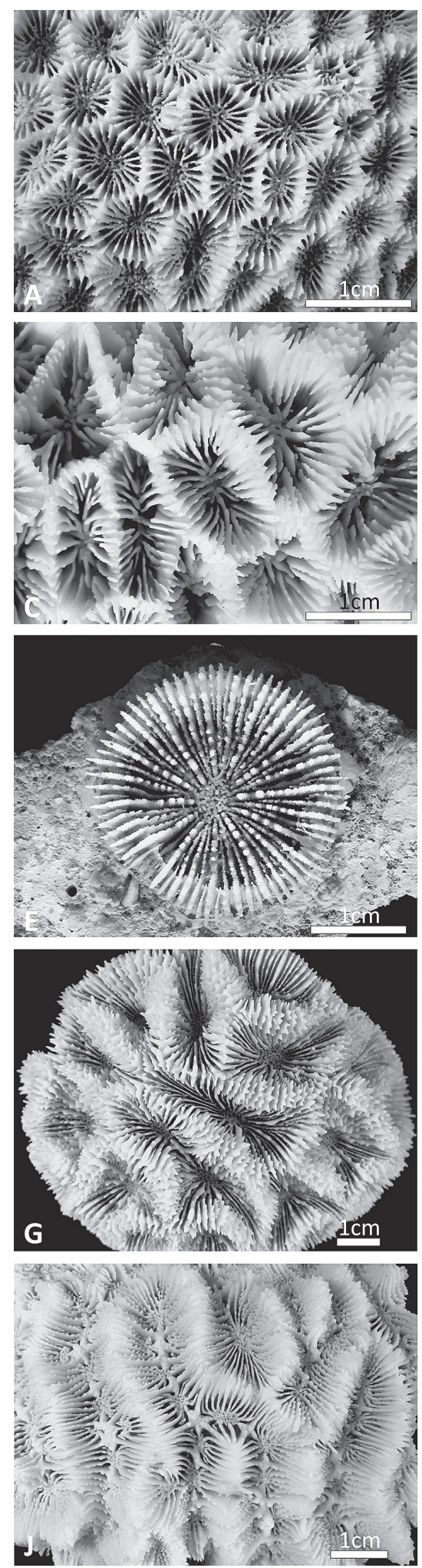
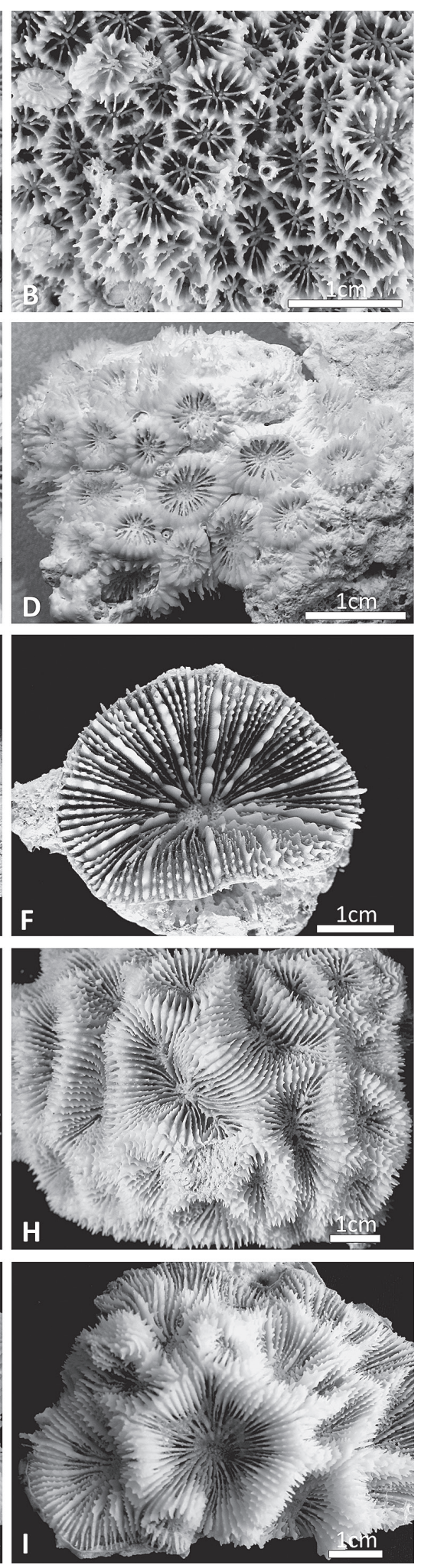

Fig. 1. Lobophylliidae included in this study. A) Holotype of Micromussa amakusensis MTQ G32485 from Japan; B) Micromussa indiana sp. nov. (referred to as Micromussa cf. amakusensis in text) from the Gulf of Aden MNHN-IK2012-14232; C) Holotype of Acanthastrea lordhowensis MTQ G57483 from Australia; D) Micromussa multipunctata (previously Montastraea) RMNH Coel 40090 from Malaysia; E) Micromussa pacifica sp. nov. (referred to as Homophyllia cf. australis in text) MNHN IK-2012-16046 from New Caledonia; F) Homophyllia australis IRD HS3524 from New Caledonia; G) Homophyllia bowerbanki (previously Acanthastrea) IRD HS3287 from New Caledonia; cf.H) Homophyllia bowerbanki (previously Acanthastrea hillae) AM MH043 from Australia; I) Australophyllia wilsoni (previously Symphyllia) from Australia J) Acanthastrea cf. hemprichii (referred in the text as Acanthastrea cf. hillae) UNIMIB BA115 from the Gulf of Aden. 

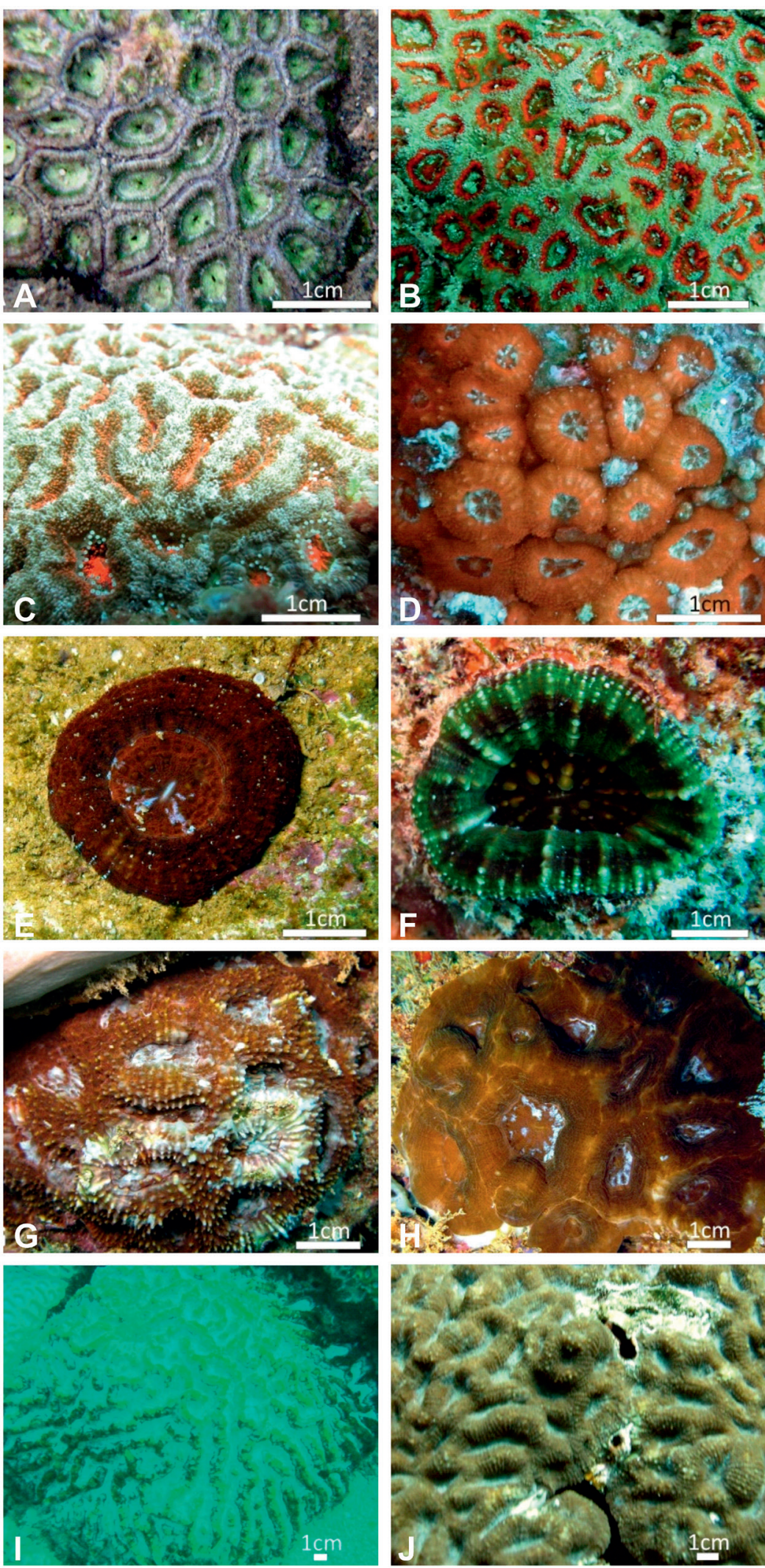

Fig. 2. Lobophylliidae included in this study in situ. A) Micromussa amakusensis from Japan; B) Micromussa indiana sp. nov. (referred to as Micromussa cf. amakusensis in text) same specimen shown in $1 \mathrm{~B}$; C) Micromussa lordhowensis (previously Acanthastrea) from Lord Howe, Australia; D) Micromussa multipunctata (previously Montastraea) same specimen shown in 1D; E) Micromussa pacifica sp. nov. (referred to as Homophyllia cf. australis in text), same specimen shown in $1 \mathrm{~F}$; F) Homophyllia australis, same specimen shown in 1E; G) Homophyllia bowerbanki (previously Acanthastrea), same specimen shown in 1I; H) Homophyllia bowerbanki (previously A. hillae) IRD HS3066 from New Caledonia; I) Australophyllia wilsoni from Australia; J) Acanthastrea cf. hemprichii (referred in the text as A. cf. hillae) same specimen shown in $1 \mathrm{H}$. 


\section{Clade A}

Clade A is composed of Micromussa amakusensis (Veron, 1990) (Figs 1A, 2A) and Montastraea multipunctata (Hodgson, 1985) (Figs 1D, 2D). The latter was formally assigned to the Lobophylliidae but its genetic placement represents a taxonomic issue that calls for a formal revision because it is not related to the type species Montastraea cavernosa (Linnaeus, 1767) (Huang et al., 2011; Arrigoni et al., 2014a). Nevertheless, no detailed morphological studies have, to date, been conducted on this species. The poorly studied type species Micromussa amakusensis has been recorded throughout the Indo-Pacific, from the Gulf of Aden to Central Indo-Pacific and West Pacific (Veron, 1990, 1992, 1993, 2000; Wallace et al., 2009; Pichon et al., 2010; Arrigoni et al., 2012; Arrigoni et al., 2014a). In the present study, material from the Indian Ocean (Figs 1B, 2B) and Pacific Ocean (Figs 1A, 2A) populations was examined for the first time through a morpho-molecular approach. In his description of $M$. amakusensis from Japan, Veron (1990) highlighted that, on the basis of macromorphology and in-situ appearance, this species resembles Acanthastrea lordhowensis Veron \& Pichon, 1982 (Figs 1C, 2C) although it has larger and less regular corallites and more septa. Nevertheless, Veron (2000) erected the genus Micromussa to include species previously ascribed to Acanthastrea with corallites less than $5 \mathrm{~mm}$ in diameter, thus excluding A. lordhowensis. Based on this criterion, Veron (2000) moved Acanthastrea minuta Moll \& BorelBest, 1984 into the genus Micromussa and also described M. diminuta Veron, 2000 from Sri Lanka. Although no genetic or micromorphological data is currently available for these two species, the type specimens were examined in this study and their taxonomic position discussed.

\section{Clade B}

Clade B sensu Arrigoni et al. (2014a) currently contains Acanthastrea bowerbanki Milne Edwards \& Haime, 1857 (Figs 1G, 2G) and A. hillae Wells, 1955 (Figs $1 \mathrm{H}, 2 \mathrm{H}$ ). At a molecular level, $A$. bowerbanki and $A$. hillae are not closely related to the type species $A$. echinata (Dana, 1846), which is recovered in clade $\mathrm{E}$ sensu Arrigoni et al. (2014a), and the establishment of a new genus to accommodate species in clade B is thus tentative. The sister-relationship between the two species is corroborated also by remarkable morphological similarities (Chevalier, 1975; Veron and Pichon, 1980; Veron, 1992, 2000; Wallace et al., 2009). Their coralla are similar in growth form and mode of budding, while their corallites are among the largest of all species currently assigned to Acanthastrea (Veron and Pichon, 1980; Veron, 2000). Furthermore, A. bowerbanki and A. hillae show a partially overlapping geographic distribution, mainly in the Central Pacific (Veron and Pichon, 1980; Veron, 1993, 2000; Wallace et al., 2009), where they are generally uncommon throughout the tropics but more abundant in high latitude and marginal reef localities (Veron, 1993). Acanthastrea hillae has been also reported from the Western Indian Ocean but these records are doubtful (Veron, 2000). For this reason, material from Yemen assigned to this species based on macromorphology was also included in this study (Figs 1J, 2J).

The monotypic genus Homophyllia has a complicated nomenclatural history (Vaughan and Wells, 1943; Wells, 1964; Veron and Pichon, 1980; Veron, 2000; Budd et al., 2012). Previously considered a junior synonym of Lobophyllia (Matthai, 1928; Vaughan and Wells, 1943) and Scolymia (Veron and Pichon, 1980; Veron, 2000), it was restored by Budd et al. (2012) following novel morphological evidence proposed by Budd and Stolarski (2009). Budd et al. (2012) showed that the micromorphology and the microstructure of the monostomatous species Homophyllia australis (Milne Edwards \& Haime, 1849) (Figs 1F, 2F) are clearly distinguished from those of the solitary species Scolymia lacera (Pallas, 1766) and Parascolymia vitiensis (Brüggemann, 1877) (Budd and Stolarski, 2009; Budd et al., 2012; Arrigoni et al., 2014b). Nevertheless, despite the increasing amount of genetic data concerning the Lobophylliidae (Arrigoni et al., 2014a, 2014b, 2015, 2016), no molecular information is available for $H$. australis. In this study we analyzed a large collection of specimens encompassing the whole range of morphological variability shown by Veron and Pichon (1980), thus including specimens with typical morphology (Budd and Stolarski, 2009: fig 2K; Veron and Pichon, 1980: figs 408, 410, 420; Figs 1F, $2 \mathrm{~F}$ ) and other specimens with thinner and less numerous septa identified as $H$. cf. australis (Veron and $\mathrm{Pi}$ chon, 1980: figs 412, 424; Figs 1E, 2E).

\section{Symphyllia wilsoni}

Symphyllia wilsoni Veron, 1985 (Figs 1I, 2I) is a relatively poorly known species, which is distributed from south to southwestern Australia (Veron, 2000) 
and ascribed to the genus Symphyllia by reason of its massive coralla with large meandering valleys. However, as remarked by Veron (2000), this species presents some odd macromorphological characters, such as small skeletal features compared to those of its congeners and septa resembling those of the genus Acanthastrea. Although several Symphyllia representatives, including the type species, were included in molecular analyses and found in clade I sensu Arrigoni et al. (2014a), S. wilsoni has previously not been examined and is therefore included in our analyses in order to ascertain its status.

The present study aims to provide a robust molecular phylogeny reconstruction of six nominal species included in clades A and B, and of S. wilsoni. We analyze material from different geographic localities spanning the known range of intraspecific morphological variability and several types of sequence data: the mitochondrial DNA regions cytochrome c oxidase subunit I (COI) as well as the non-coding intergenic spacer region between COI and large ribosomal RNA subunit, and the nuclear markers ribosomal internal transcribed spacers 1 and 2 (ITS region) and the histone $\mathrm{H} 3$ gene. Furthermore, we investigate gross- and fine-scale morphology of skeletons of each coral species, including material from each type locality, except for M. multipunctata, which was sampled from the northernmost tip of Borneo (Waheed et al., 2015).

\section{Material and methods}

\section{Coral sampling and identification}

A total of 87 coral specimens ascribed to Acanthastrea bowerbanki, A. echinata, A. hillae, A. lordhowensis, Homophyllia australis, Micromussa amakusensis, Montastraea multipunctata, and Symphyllia wilsoni, were collected while SCUBA diving between 1 and 35 $\mathrm{m}$ depth from different localities in the Indian and $\mathrm{Pa}$ cific Ocean and analyzed from both molecular and morphological point of view (S1). Furthermore, the lectotype of M. diminuta and the holotype of A. minu$t a$ were used in the morphological analysis. Samples of A. bowerbanki, A. hillae, A. lordhowensis, H. australis, and $S$. wilsoni were sampled from their type locality, Australia, as well as M. amakusensis from Japan. Each coral sample was photographed underwater and then collected, tagged, and approximately $1 \mathrm{~cm}^{2}$ of the entire specimen was broken off and put in CHAOS solution (not an acronym; $4 \mathrm{M}$ guanidine thiocyanate,
0.1\% N-lauroyl sarcosine sodium, $10 \mathrm{mM}$ Tris $\mathrm{pH}$ 8, $0.1 \mathrm{M}$ 2-mercaptoethanol) to dissolve the tissue or fixed in $95 \%$ ethanol for further molecular analyses. The remaining corallum was immersed in sodium hypochlorite for 48 hours to remove all tissues, rinsed in freshwater and air-dried for identification and microscope observations (Figs 1,2). Specimens were identified at species level based on their morphological structures following Milne Edwards and Haime (1848), Wells (1964), Veron and Pichon (1980, 1982), Hodgson (1985), Veron (1985, 1990, 2000), Wallace et al. (2009), and Pichon et al. (2010), as well as referring to illustrations of holotypes in their original descriptions. Voucher samples were deposited at the University of Milano-Bicocca (UNIMIB, Milano, Italy), the Australian Museum (AM, Sydney, Australia), the Institut de Recherche pour le Développement (IRD, Nouméa, New Caledonia), the Seto Marine Biological Laboratory at the Kyoto University (SMBL, Kyoto, Japan), the University of Miyazaki (Miyazaki, Japan), Naturalis Biodiversity Center (RMNH, Leiden, the Netherlands), and the Museum of Tropical Queensland (MTQ, Townsville, Australia).

\section{DNA preparation, amplification, and sequence analyses}

Total genomic DNA was extracted using the DNeasy Blood and Tissue kit (Qiagen Inc., Hilden, Germany) from coral tissue preserved in ethanol or using a phenol-chloroform-based method with a phenol extraction buffer (100 mM Tris-Cl pH 8, 10 mM EDTA, 0.1\% SDS) from specimens conserved in CHAOS solution (Fukami et al., 2004a; Huang et al., 2011). For all coral samples, we amplified and directly sequenced one mitochondrial marker (COI) and two nuclear markers (histone H3 and ITS region). The COI gene, histone $\mathrm{H} 3$, and ITS region were amplified using the primer pairs MCOIF and MCOIR and the protocol proposed by Benzoni et al. (2011), H3F and H3R (Colgan et al., 1998), ITS4 (White et al., 1990) and A18S (Takabayashi et al., 1998) and the protocol published by Benzoni et al. (2011), respectively. Furthermore, for species included in clade A sensu Arrigoni et al. (2014a), IGR was amplified using MNC1F and MNC1R primers (Fukami et al., 2004b; Huang et al., 2009) and the protocol described by Arrigoni et al. (2016). All PCR products were purified with Illustra ExoStar (GE Healthcare, Buckinghamshire, UK) and directly sequenced in both strands using an ABI 3130xl Genetic Analyzer (Applied Biosystems, Carlsbad, CA, 


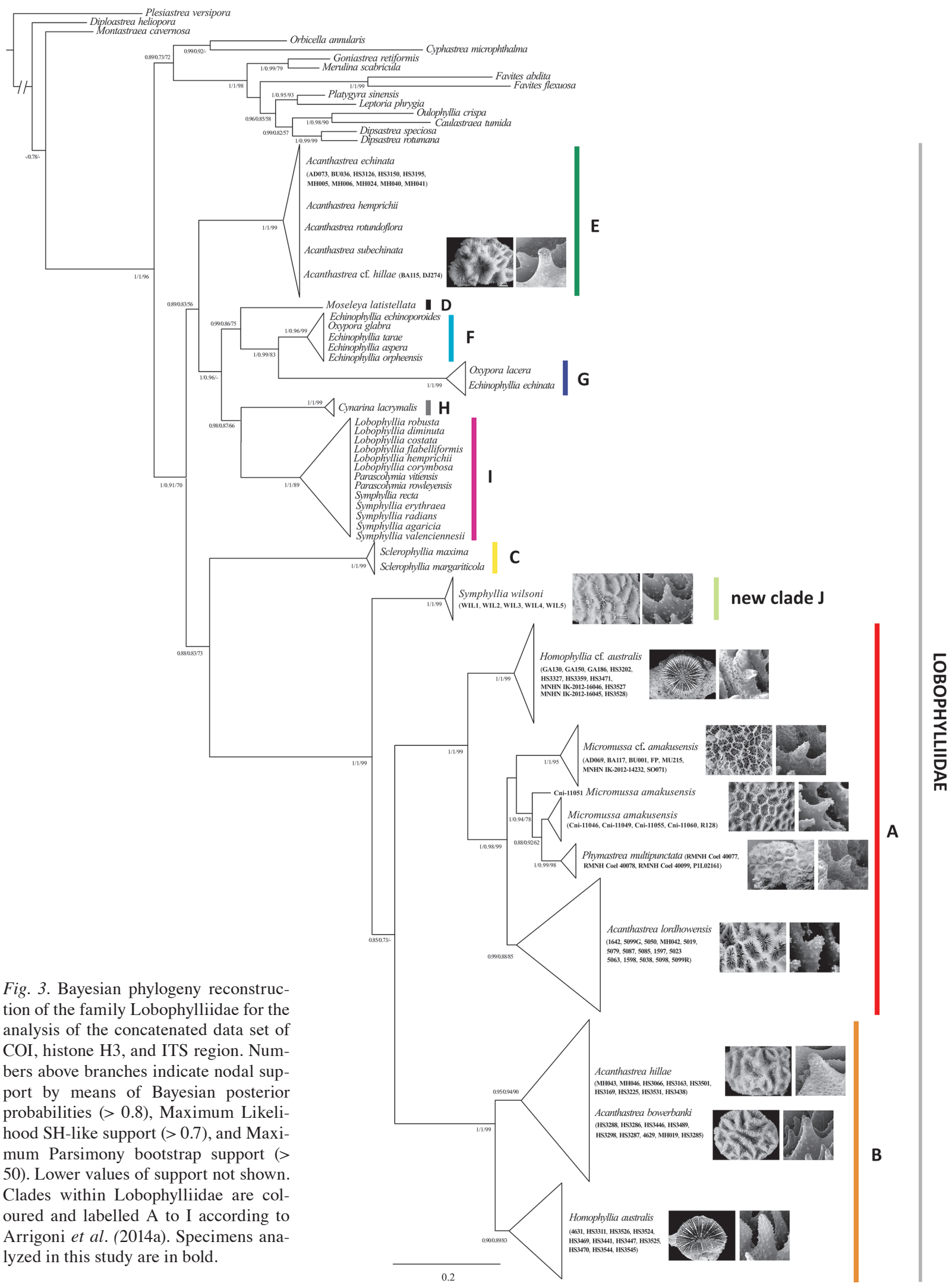


USA). Chromatograms were manually corrected for misreads, if necessary, and forward and reverse strands were merged into one sequence file using CodonCode Aligner 3.6.1 (CodonCode Corporation, Dedham, MA, USA). In particular, chromatograms of products obtained with ITS4 and A18S primers did not show any intra-individual polymorphisms or double peaks, thereby allowing direct sequencing of this region. All newly obtained sequences were deposited in EMBL, and accession numbers are listed in S1.

Sequence alignments were generated using the EINS-i option in MAFFT 7.130b (Katoh et al., 2002; Katoh and Standley, 2013) under default parameters. For phylogenetic analyses, sequences of COI, histone H3, and ITS region were concatenated into one partitioned dataset. Three methods, maximum parsimony (MP), maximum likelihood (ML), and Bayesian inference (BI), were employed to reconstruct the phylogenetic relationships within the Lobophylliidae. For MP analysis, tree searches were generated in PAUP* $4.0 \mathrm{~b} 10$ (Swofford, 2003) using heuristic searches with 10000 random additions. Branch support was estimated with the bootstrap confidence levels using 1000 replicates. Prior to the model-based phylogenetic analyses, the best-fit model of nucleotide substitution was identified for each gene partition separately by means of the Akaike Information Criterion calculated with MrModeltest 2.3 (Nylander, 2004). The following substitution models were suggested: the GTR $+\mathrm{I}+\mathrm{G}$ for ITS region, the HKY + G + I for COI, and the $\mathrm{K} 80+\mathrm{I}$ for histone H3. ML topologies were calculated with PhyML (Guindon and Gascuel, 2003) and relative support for individual clades was estimated using the Shimodaira and Hasegawa (SH-like) test. BI analysis was performed employing MrBayes 3.1.2 (Huelsenbeck and Ronquist, 2001). Two simultaneous runs of four Markov Monte Carlo chains were conducted for $3 \mathrm{x}$ $10^{7}$ generations, sampling every 100 generations to ensure independence of the successive samples. Results were analyzed for stationarity and convergence using Tracer 1.6 (Rambaut and Drummond, 2009), with a burn-in of $25 \%$ of sampled generations. Additionally, ML phylogenetic reconstructions for each separate COI, histone $\mathrm{H} 3$, and ITS region were obtained using PhyML (Guindon and Gascuel, 2003) under the substitution models proposed by MrModeltest 2.3 (Nylander, 2004). The SH-like test replicates was performed to assess the branch support of ML trees. Within clade A sensu Arrigoni et al. (2014a), Network 4.6.1.2 (http://www.fluxus-technology.com) was used to construct a median-joining haplotype network
(Bandelt et al., 1999) for the IGR dataset. This method is especially applicable to non-recombinant DNA sequences, such as mitochondrial DNA, and combines all minimum spanning trees into a single network. Alignment was converted to the Roehl format using DnaSP (Librado and Rozas, 2009), invariable sites were removed and sites with gaps were not considered.

\section{Morphological analyses}

Scleractinian coral skeletons of the sequenced lobophylliids were analyzed both at macro- and micromorphological levels using light microscopy and Scanning Electron Microscopy (SEM), respectively, in order to find morphological characters supporting the molecular phylogeny reconstructions. Images of coral skeletons were taken with a Canon G5 digital camera as well as with a Leica M80 microscope equipped with a Leica IC80HD camera. For scanning electron microscope (SEM) imaging, skeleton fragments were ground to produce a flat edge, mounted on stubs using silver glue, sputter-coated with conductive gold film, and examined using a Vega Tescan Scanning Electron Microscope at the University of Milano-Bicocca. At least five different corallites per species were examined at micromorphological level. For a glossary of skeletal terms we followed Budd et al. (2012) and we also adopted their character names, ID numbers (in brackets), and state names. In addition to samples deposited in the institutions mentioned earlier, we analyzed specimens and type material from the Environment Protection Authority, Sana'a and Socotra, Yemen (EPA S), the Muséum National d'Histoire Naturelle (MNHN, Paris, France), the Natural History Museum (NHMK, London, UK, formerly British Museum of Natural History, $\mathrm{BMNH}$ ), the Queensland Museum (QM, Brisbane, Australia), the Marine Science Institute, University of the Philippines (UP, Manila, the Philippines), and the Western Australian Museum (WAM, Perth, Australia).

\section{Results}

\section{Molecular phylogenetic and haplotype network analyses}

New sequence data of COI, histone H3, and ITS region, generated in this study from 87 coral samples representing 11 species, were combined with published sequences of the families Lobophylliidae, Merulinidae Verrill, 1865, Diploastraeidae Chevalier \& Beau- 
vais, 1987, and Montastraeidae Yabe \& Sugiyama, 1941, resulting in an alignment composed of 50 nominal species. Plesiastrea versipora was selected as outgroup because of its divergence from the Lobophylliidae, Merulinidae, Diploastraeidae, and Montastraeidae (Fukami et al., 2008; Benzoni et al., 2011; Huang et al., 2011; Budd et al., 2012). The final concatenated dataset of aligned sequences of the three molecular fragments had a total length of 1939 bp (COI: $580 \mathrm{bp}$, histone H3: 318 bp, ITS region: $1041 \mathrm{bp})$. The ITS region was the most variable, with 191 variable sites (148 positions parsimony-informative $\mathrm{PI}$ ), the COI gene fragment showed 87 bp variable sites (57 positions PI), and the histone $\mathrm{H} 3$ sequences featured $90 \mathrm{bp}$ variable sites (84 positions $\mathrm{PI}$ ).

The three single gene trees did not show any supported topological conflicts, although the resolution differed notably among the three topologies (Figs S3S5). Nevertheless, each of the analyzed specimens belonged to the same molecular clade in all of the three phylogenetic reconstructions. Bayesian, maximum likelihood, and maximum parsimony topologies were highly concordant and node support values were high across the ingroup and outgroup.

The phylogram based on the concatenated (COI, histone H3, and ITS region) molecular datasets was broadly consistent with previously published phylogeny reconstructions (Huang et al., 2011; Arrigoni et al., 2014a, 2014b, 2015), confirming the Lobophylliidae and Merulinidae as monophyletic taxa (Fig. 3). All of the nine main genus-level lineages proposed by Arrigoni et al. (2014a) for the Lobophylliidae were highly supported by all methods of phylogeny reconstruction.
Clades A and B were sister taxa of each other. Both were well resolved and strongly supported (Bayesian posterior probability score $\mathrm{Pp}=1$, ML SH-like support Ss $=1$, MP bootstrapping support Bs $=99$ for both clades). A close-up of the phylogenetic relationships among and within clades A and B is shown in Fig. S6. Clade A contained three nominal species: the type species of the genus Micromussa, M. amakusensis, along with Montastraea multipunctata and A. lordhowensis. The monophyly of the latter two species was highly supported whereas M. amakusensis was split into two main lineages. In particular, the colonies of M. amakusensis from the type locality Japan were grouped together and sister to Montastraea multipunctata, with the exception of the uncertain position of one sample SMBL Cni-11051. In contrast, specimens of M. cf. amakusensis from Yemen formed a monophyletic lineage with strong support $(\mathrm{Pp}=1, \mathrm{Ss}=1, \mathrm{Bs}=95)$ that was sister to the group containing M. amakusensis from Japan and Montastraea multipunctata. Within clade A, we found a well-supported basal group $(\mathrm{Pp}=1$, $\mathrm{Ss}=1$, $\mathrm{Bs}=99)$ composed of all of the specimens identified as Homophyllia cf. australis (Figs 1E, 2E). This lineage was not closely related to the one including the specimens of $H$. australis that showed the typical morphology (Figs 1F, 2F) which formed a well-supported group $(\mathrm{Pp}=0.9, \mathrm{Ss}=0.89, \mathrm{Bs}=83)$ within clade B. Homophyllia australis was instead sister to the well-supported lineage $(\mathrm{Pp}=0.95, \mathrm{Ss}=0.94, \mathrm{Bs}=90)$ composed of $A$. bowerbanki and $A$. hillae. The latter two species could be distinguished using these three molecular markers as the average genetic distance between these two species was $2.3 \pm 0.3 \%$, and fully overlapped with

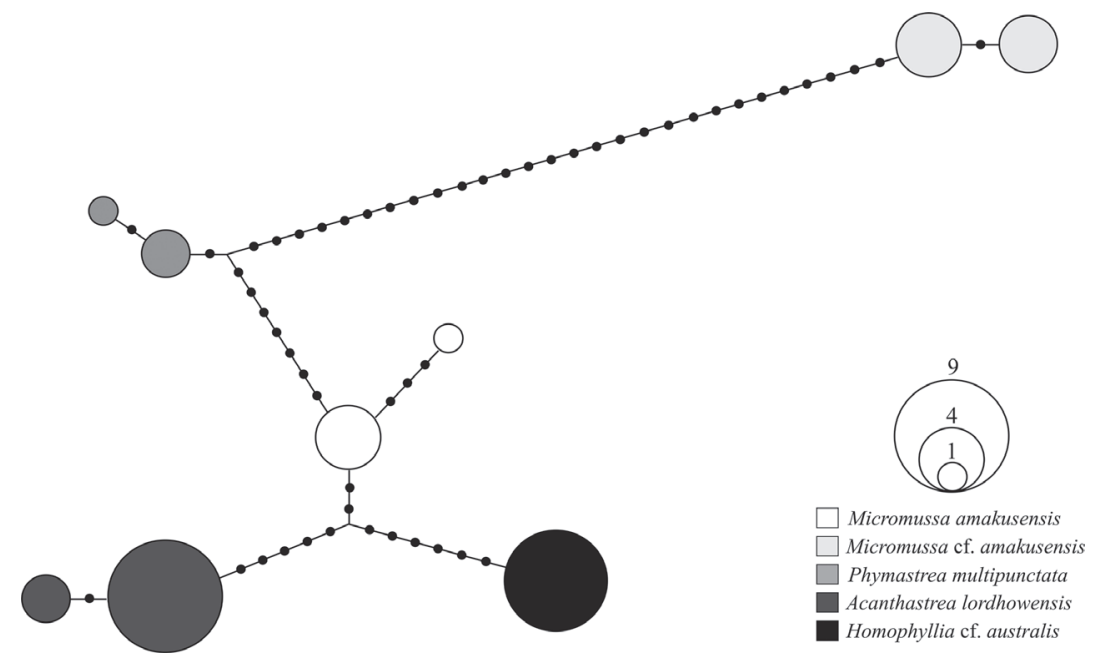

Fig. 4. Haplotype network of clade A obtained in Network 4.6.1.2 for the mitochondrial intergenic spacer region (IGR) between COI and 1-rRNA. The size of circles is proportional to the frequencies of specimens sharing the same haplotype. The black solid circles are indicative of mutations that differentiate each haplotype. 
Table 1. Macromorphology and micromorphology of the Lobophylliidae examined in this study. Explanation of characters, their ID numbers (in brackets) and state names are from Budd et al. (2012) $*$ = character examined on polycentric coralla; ${ }^{\circ}=$ a central larger corallite may be observed; $\S=$ in series, $>1 / 4$ in uniserial corallites; Csn = number of cycle of costosepta; $\mathrm{Sn}=$ number of cycle of septa.

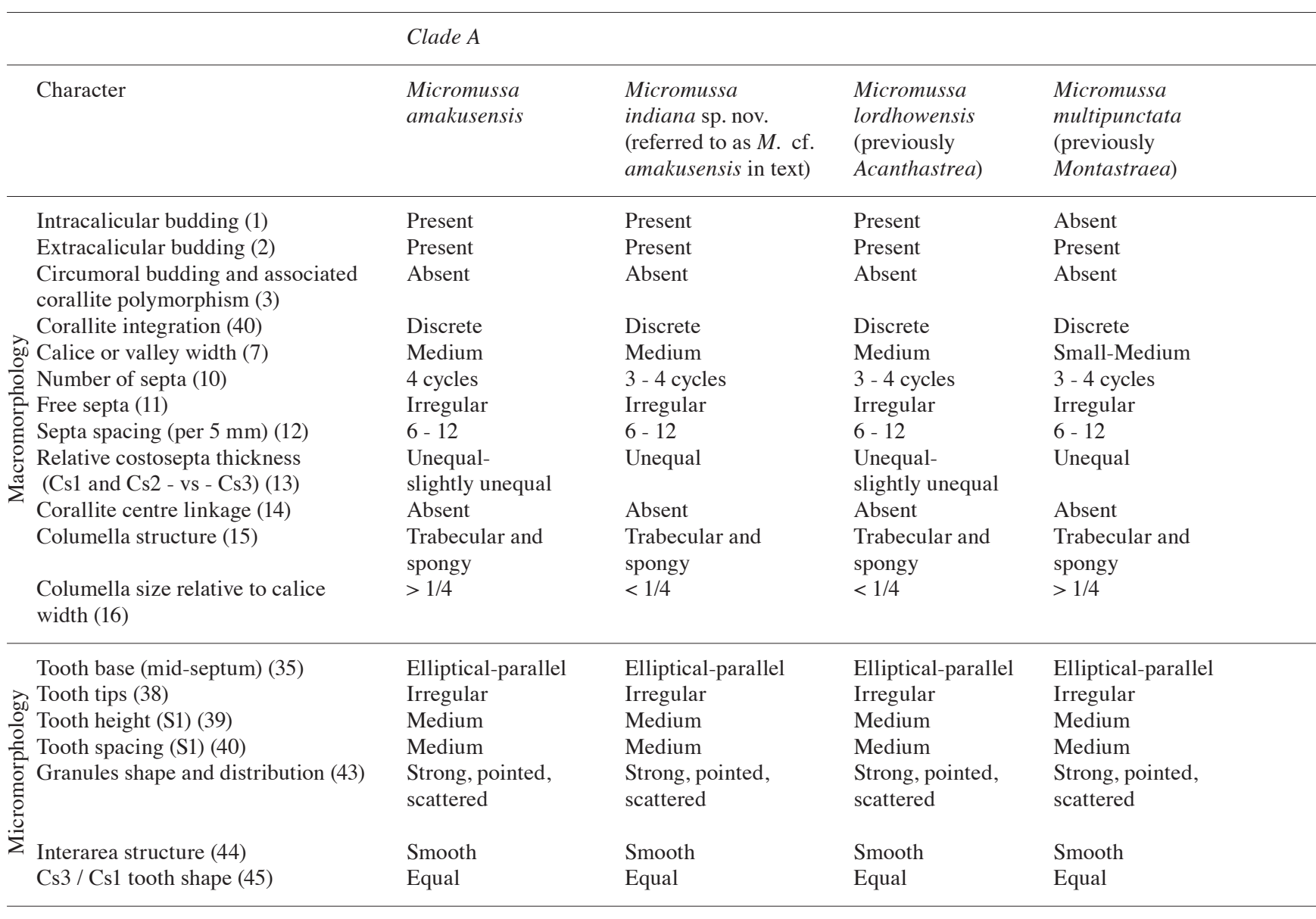

the intraspecific distances within $A$. bowerbanki and $A$. hillae that are $2.1 \pm 0.3 \%$ and $2.4 \pm 0.4 \%$, respectively. Finally, all of the analyzed colonies of A. echinata grouped within clade $\mathrm{E}$, together with the Indian Ocean specimen of $A$. cf. hillae (Fig. 1J, 2J) and published sequences of A. rotundoflora, A. subechinata, and $A$. hemprichii, although the genetic boundaries at species level within this clade remain unclear. Surprisingly, within this family a novel clade was detected that comprised $S$. wilsoni exclusively with a very strongly supported lineage monophyly $(\mathrm{Pp}=1, \mathrm{Ss}=1, \mathrm{Bs}=99)$, that was deeply divergent from clade I, which contains the genera Lobophyllia, Parascolymia, and all of the other Symphyllia species analyzed so far. Symphyllia wilsoni fell at the base of the sister clades A and B.

The final alignment of IGR data consisted of 1608 bp, of which 52 positions were variable. Haplotype network analysis of clade A, as inferred from the mtDNA IGR locus, was highly concordant with the phylogeny reconstruction of clade A based on COI, histone H3, and ITS region (Fig. 4). A total of nine haplotypes were detected and five main clusters, corresponding to the five lineages found using the other markers, were revealed. These clusters were separated by a minimum of eight substitutions (between M. amakusensis from Japan and A. lordhowensis) and no haplotypes were shared between two or more clusters. In particular, we found two closely related haplotypes specific to $M$. amakusensis from Japan and differing by three base changes, two closely related haplotypes for Montastraea multipunctata separated by one substitution, two closely related haplotypes specific of A. lordhowensis showing one mutation event, a single haplotype for all eight specimens of $H$. cf. australis, and two closely re- 


\begin{tabular}{|c|c|c|c|c|c|}
\hline & Clade B & & & Clade J & Clade E \\
\hline $\begin{array}{l}\text { Micromussa } \\
\text { pacifica sp. nov. } \\
\text { (referred to as } H \text {. } \\
\text { cf. australis in text) }\end{array}$ & $\begin{array}{l}\text { Homophyllia } \\
\text { australis }\end{array}$ & $\begin{array}{l}\text { Homophyllia } \\
\text { bowerbanki } \\
\text { (previously A. } \\
\text { bowerbanki) }\end{array}$ & $\begin{array}{l}\text { Homophyllia } \\
\text { bowerbanki } \\
\text { (previously } \\
\text { A. hillae) }\end{array}$ & $\begin{array}{l}\text { Australophyllia } \\
\text { wilsoni } \\
\text { (previously } \\
\text { Symphyllia) }\end{array}$ & $\begin{array}{l}\text { Acanthastrea } \\
\text { hemprichii } \\
\text { (referred to as } \\
\text { A. cf. hillae in text) }\end{array}$ \\
\hline Present* & Present* & Present & Present & Present & Present \\
\hline Present* & Present* & Present & Present & Present & Present \\
\hline Absent & Absent & Absent & Absent & Absent & Absent \\
\hline Discrete & Discrete & Discrete & Discrete & Uniserial & Discrete \\
\hline Large & Large & Large & Large & Medium & Large \\
\hline$>4$ cycles & $>4$ cycles & $>4$ cycles & $>4$ cycles & $>4$ cycles & $>4$ cycles \\
\hline Irregular & Irregular & Irregular & Irregular & Irregular & Irregular \\
\hline $6-12$ & $6-12$ & $6-12$ & $6-12$ & $6-12$ & $6-12$ \\
\hline $\begin{array}{l}\text { Unequal- } \\
\text { slightly unequal }\end{array}$ & Unequal & $\begin{array}{l}\text { Unequal- } \\
\text { slightly unequal }\end{array}$ & Unequal & Unequal & Unequal \\
\hline Absent & Absent & Absent & Absent & Discontinuous & Absent \\
\hline $\begin{array}{l}\text { Trabecular and } \\
\text { spongy }\end{array}$ & $\begin{array}{l}\text { Trabecular and } \\
\text { spongy }\end{array}$ & $\begin{array}{l}\text { Trabecular and } \\
\text { spongy }\end{array}$ & $\begin{array}{l}\text { Trabecular and } \\
\text { spongy }\end{array}$ & $\begin{array}{l}\text { Trabecular and } \\
\text { spongy }\end{array}$ & $\begin{array}{l}\text { Trabecular and } \\
\text { spongy }\end{array}$ \\
\hline$<1 / 4$ & $<1 / 4$ & $<1 / 4$ & $<1 / 4$ & $<1 / 4 \S$ & $<1 / 4$ \\
\hline Elliptical-parallel & Elliptical-parallel & Elliptical-parallel & Elliptical-parallel & Elliptical-parallel & Elliptical-parallel \\
\hline Irregular & Irregular & Irregular & Irregular & Irregular & Irregular \\
\hline High & High & High & High & Medium & Medium to high \\
\hline Medium & Wide & Wide & Wide & Medium & Medium to wide \\
\hline $\begin{array}{l}\text { Strong, pointed, } \\
\text { scattered }\end{array}$ & $\begin{array}{l}\text { Weak, rounded, } \\
\text { uniformly } \\
\text { distributed }\end{array}$ & $\begin{array}{l}\text { Weak, rounded, } \\
\text { uniformly } \\
\text { distributed }\end{array}$ & $\begin{array}{l}\text { Weak, rounded, } \\
\text { uniformly } \\
\text { distributed }\end{array}$ & $\begin{array}{l}\text { Weak, rounded, } \\
\text { scattered }\end{array}$ & $\begin{array}{l}\text { Weak, rounded, } \\
\text { enveloped by } \\
\text { thickening deposits }\end{array}$ \\
\hline Smooth & Smooth & Smooth & Smooth & Smooth & Smooth \\
\hline Equal & Equal & Equal & Equal & Equal & Unequal \\
\hline
\end{tabular}

lated haplotypes for M. amakusensis from Yemen differing by one base changes. Notably, M. amakusensis from Japan and $M$. cf. amakusensis from Yemen were distantly related and separated by $35-39$ substitutions.

\section{Macromorphology}

The examined lobophylliid species presented a wide array of corallum macromorphology and corallite size and organization. Homophyllia australis (Figs 1F, 2F, $10,11,12 \mathrm{~A}$ ) and $H$. cf. australis (Figs 1E, 2E, 8, 9, 12D) were solitary forming large and predominantly monocentric coralla. Micromussa amakusensis (Figs 1A, 2A, 7A), M. cf. amakusensis (Figs 1B, 2B, 5, 6, 7D), A. lordhowensis (Figs 1C, 2C, S5, S6), Montastraea multipunctata (Figs 1D, 2D, S9, S10), A. hillae (Figs 1H, 2H, S13A, C, E, G), A. cf. hillae (Figs 1J, 2J),
A. bowerbanki (Figs 1G, 2G, S13B, D, F, H) and $S$. wilsoni (Figs 1I, 2I, 13) were colonial species forming encrusting to massive coralla. Corallite organization was cerioid in M. amakusensis (Fig. 1A), M. cf. amakusensis (Fig. 1B), and A. lordhowensis (Fig. 1C); plocoid in Montastraea multipunctata (Fig. 1D); cerioid to sub-meandroid in A. hillae (Fig. 1H) and $A$. bowerbanki (Fig. 1G); and mainly meandroid in S. wilsoni (Fig. 1I).

In all the examined species, both intracalicular and extracalicular budding occurred (Table 1). Although polystomatous coralla were observed in both Homophyllia australis and $H$.cf. australis, a more pronounced tendency to polystomatism was observed in the examined series of the latter (Figs 8C-I, 9D-H, S11). Both intracalicular (Fig. 8C) and extracalicular (Fig. 8F-I) modes of budding were observed in $H$. cf. australis. In 

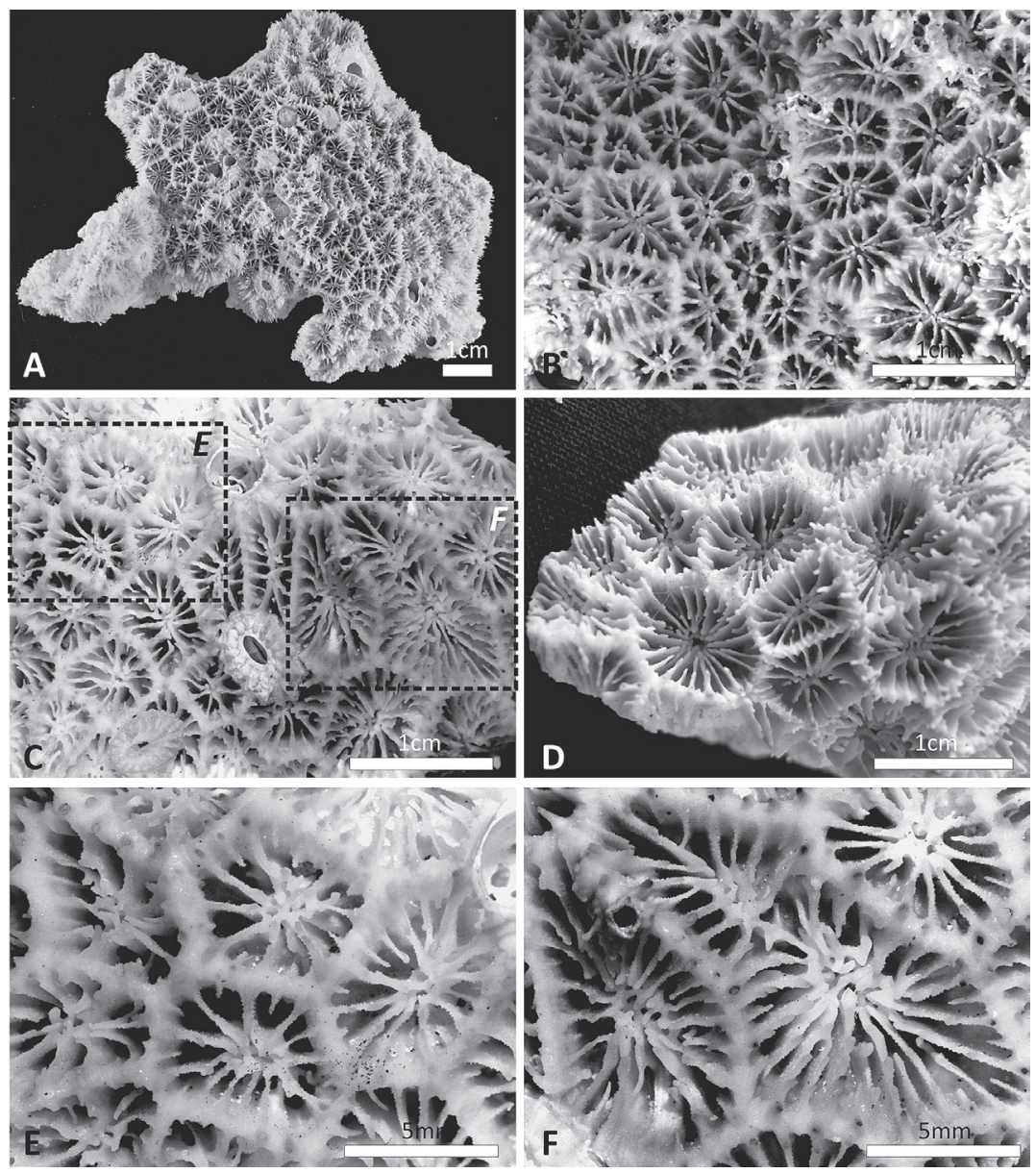

Fig. 5. Micromussa indiana sp. nov. (referred to as Micromussa cf. amakusensis in text) from the Gulf of Aden, Indian Ocean. A) Corallum morphology of specimen MNHN-IK-2012-14232; B) Detail of the same specimen as in $\mathrm{A} ; \mathrm{C}$ ) Within specimen variability of UNIMIB MU183; D) EPA S C3695, specimen from Socotra Island with some larger corallites than the specimen in A and B; E-F) Close ups of adjacent parts of the specimen in $\mathrm{C}$ having smaller and larger corallites, respectively. specimens where the former occured, adjacent centers were linked by lamellar linkage (Fig. 8C).

Circumoral budding and associated corallite polymorphism was not observed in any of the examined taxa (Table 1). However, in specimens identified as $A$. bowerbanki a larger central corallite was observed (Figs S13B, D, F, H, S14B, D, F, H) following Veron (2000) (Table 1). Veron (2000, vol. 3, p. 26) remarked that in colonies of this species "a central corallite is usually conspicuous", but he did not mention this character for A. hillae. However, a larger corallite undergoing intracalicular budding was observed roughly at the center of the holotype of this species (Fig. S13A) as well as in the holotype of A. bowerbanki (Fig. S13B) and in some specimens illustrated by Veron and Pichon (1980: figs 441, 443).

The only species with meandroid corallite arrangement was S. wilsoni (Table 1) (Figs 1I, 13A-B). Although these were generally uniserial and discontinu- ous, in some cases a biserial condition was almost attained. In fact, in this species centers within a series were linked by a thick lamellar process which in some cases seemed to actually split the columella in two, giving it a bilateral symmetry (Fig. 13C). Symphyllia wilsoni was also the only species among those we examined or (to our knowledge) in the Lobophylliidae to form monticules (Fig. 13A, E-G) resembling the hydnophores typical of the merulinid genus Hydnophora Fischer von Waldheim, 1807 and of the agariciid Pavona varians Verrill, 1864. These monticules formed "where sections of common wall between corallites intersect and develop into conical mounds" (Veron, 2000: vol. 2, p. 346).

With reference to the ranges set by Budd et al. (2012), calices were large (>15 mm) in A. bowerbanki, A. hillae, A. cf. hillae, H. australis, and H. cf. australis, medium (8-15 mm) in S. wilsoni, M. amakusensis, $M$. cf. amakusensis, and A. lordhowensis, and small to me- 
dium (3 - $9 \mathrm{~mm}$ ) in Montastraea multipunctata (Table 1). Within the examined series of specimens, the largest corallites of $H$. australis (Fig. S12) reached larger dimensions than those of $H$. cf. australis (Fig. S11). Among the species with medium sized corallites, $M$. amakusensis had overall larger and more regularly shaped corallites than M. cf. amakusensis (Figs 1A, 7A and Figs 1B, 7D, respectively). The latter displayed a more variable corallite diameter and outline (Fig. 5). In fact, although some coralla can display corallites with a larger diameter and more regular shape (Fig. 5C-D) and resembled those of the typical M. amakusensis, in these specimens the within corallum variability for these characters was remarkable (Fig. 5C, E-F). Acanthastrea lordhowensis had larger corallites than $M$. amakusensis and $M$. cf. amakusensis. In this species too, corallite shape showed high variability ranging from irregularly polygonal and elongated (Fig. S7A-B) to a more regular outline (Fig. S7E). Such intraspecific variability was also obvious in situ (e.g. see Fig $8 \mathrm{C}$ with rounded polyps and Fig. 8G with irregularly shaped and elongated polyps). In the plocoid Montastraea multipunctata, corallite shape was less variable, ranging from round to oval in larger corallites although smaller corallites can be more irregular (Figs S9, S10).

With respect to the number of septa, Acanthastrea lordhowensis, Microsmussa cf. amakusensis, and Montastraea multipunctata had 3 - 4 cycles of septa while 4 cycles were found in M. amakusensis. More than 4 cycles were observed in all the other examined species. All examined species shared the presence of irregular free septa and a similar spacing of septa (611 per $5 \mathrm{~mm}$ ).

Costosepta were unequal in relative thickness between those of the first two orders and those of the third order in M. cf. amakusensis, Montastraea multipunctata, H. australis, A. hillae, A. cf. hillae, and S. wilsoni, while in the remainder of the examined species costosepta were unequal to slightly unequal (Table 1), showing a certain intraspecific variability of this character. Notably, the thickness of costosepta in A. bowerbanki was only slightly unequal in the holotype (Fig. S13B) and in some of the other examined specimens (Fig. S13D, F, H). Similarly, this character showed an obvious variability also in the examined specimens of A. hillae (Fig. S13A, C, E, G). In S. wilsoni the unequal costosepta thickness was particularly obvious especially within the series of corallites where thicker septa reach and fuse with the lamellar process uniting the centers (Fig. 13B-C). As a result, thicker costosepta alternated with series centers in this species.
The columella was trabecular, spongy and smaller than $1 / 4$ of the diameter of the calice in all species except M. amakusensis and Montastraea multipunctata, where it was consistently larger (Table 1). The dimension of the columella (relative to the calice width) was quite variable in $S$. wilsoni where it was smaller in series of corallites (Fig. 13B, D) and larger in monocentric corallites (Fig. 13B).

\section{Micromorphology}

Despite the above-mentioned macromorphological variability of skeletal structures (Table 1), all the examined taxa shared similar micromorphology and, in particular, have septal teeth with an elliptical base at mid-septum and irregular tooth tips.

Septal tooth height was medium $(0.3-0.6 \mathrm{~mm})$ in M. amakusensis, M. cf. amakusensis, A. lordhowensis, Montastraea multipunctata, and S. wilsoni; medium to high in A. cf. hillae; and high (>0.6 mm) in H. australis, $H$. cf. australis, A. hillae, and A. bowerbanki (Table 1) (Fig. 14). Both Wells (1955), in his original description of A. hillae, and later Chevalier (1975) remarked that in this species septal teeth tend "to be relatively small near tops of walls and increasing greatly in height toward the columella, especially in the case of the longer septa but decreasing again at the inner ends of the septa" (Wells, 1955) (Fig. S13A). We observed the same variation in septal teeth height in the septa of the first and second cycle in all examined specimens of A. hillae (e.g. Fig. S13C, E, G). Although the same was not observed in the holotype of A. bowerbanki, which have thinner septa than the holotype of A. hillae, this peculiar within-septum tooth height variation was observed in several specimens of this species (Fig. 5D, F, H), although it was less obvious in specimens with thinner septa (Fig. 5H). The same pattern in septal teeth height variation was consistently observed in all examined specimens of $H$. australis (Fig. 10B-D, F-H), but not in those of $H$. cf. australis (Figs 8, 10E-F), in which septal teeth of the first two cycles decreased in height from the wall to the columella. In A. lordhowensis, although septal teeth were of uniform height within septa, a certain degree of intraspecific variation of this character was observed with some specimens having more developed teeth (Fig. S7C, F) than others (Fig. S7D-E).

Although septal tooth size varied between cycles of septa (being larger in those of lower orders and smaller in those of higher orders) their shape was consistently uniform within the same species in all cases except $A$. 

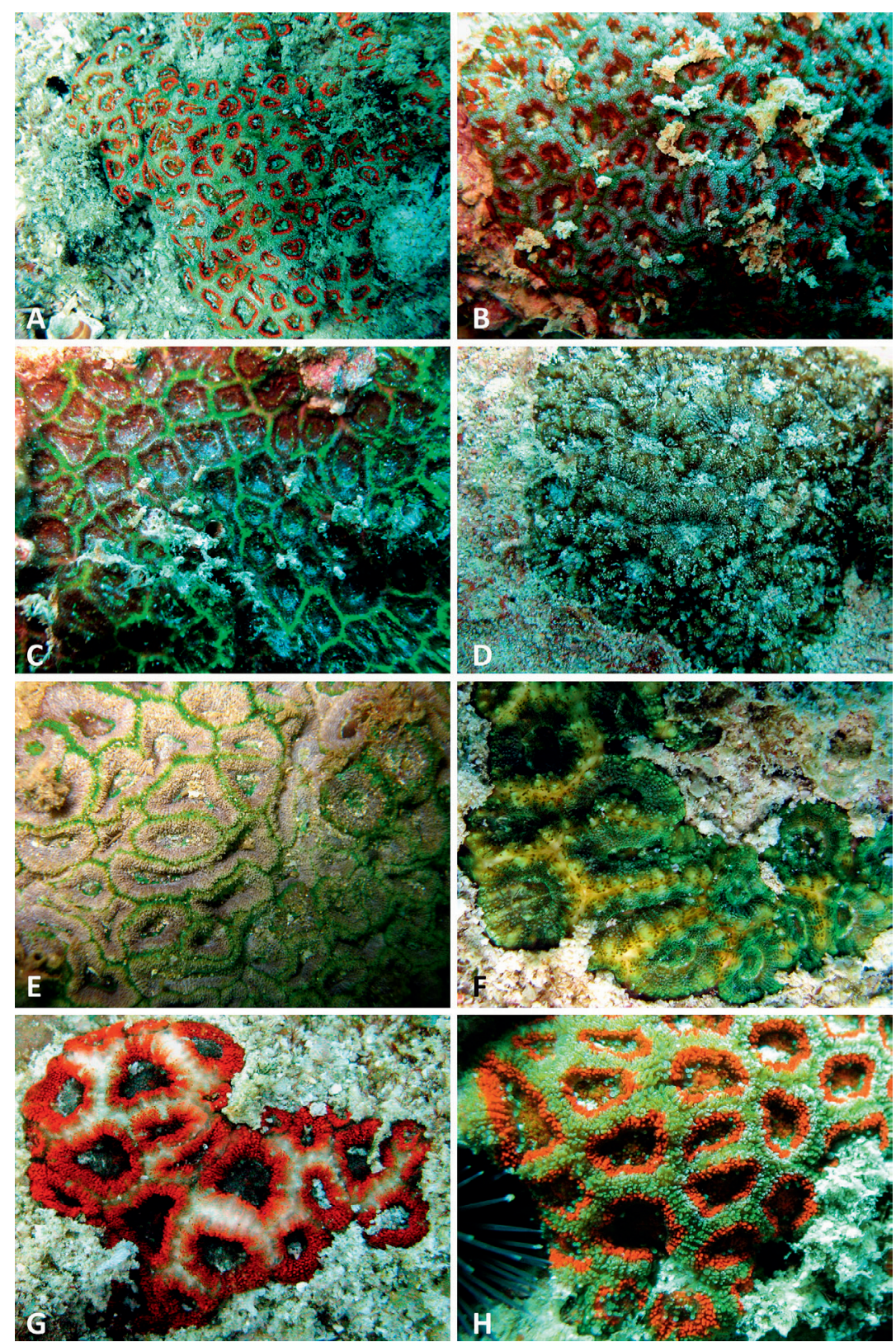

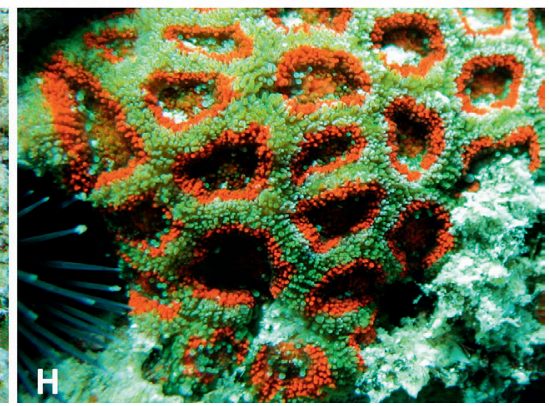

Fig. 6. Micromussa indiana sp. nov. (referred to as Micromussa cf. amakusensis in text) in situ. A) Specimen UNIMIB MU215 showing a beige colouration with red polyp outline at Al Mukallah; B) Colony with retracted polyps having a green, light grey and red colouration at Hyllanyia Island, Bir Ali; C) Burum; D) Al Badi Island, Kamaran Islands, Southern Red Sea; E) Colony with irregularly shaped polyps at Habban Island, Aden; F) Colony with a green brown morph at Di Hamri, Socotra Island, this colony was found at the same site as the one in G; G) Di Hamri, Socotra Island white red morph sympatric with $F$; $H$ ) Hyllanyia Island, Bir Ali. cf. hillae (Table 1). Tooth spacing was wide (> 1.0 $\mathrm{mm})$ in $H$. australis, A. hillae, and A. bowerbanki (Fig. 14L-Q) and medium $(0.3-1.0 \mathrm{~mm})$ in all the other species. Inter-area structure was smooth in all species (Table 1). Septal side granulation was weak, rounded, and uniformly distributed in $H$. australis, $A$. hillae, and A. bowerbanki (Fig. 14P-R); weak, rounded, and scattered in S. wilsoni (Fig. 14S); weak, rounded and enveloped by thickening deposits in $A$. cf. hillae (Fig. 14T); strong, pointed and scattered in
M. amakusensis, $M$. cf. amakusensis, A. lordhowensis, Montastraea multipunctata, and $H$. cf. australis (Fig. 14F-J) (Table 1).

A peculiar micromorphology was observed in $S$. wilsoni where columellae in series of corallites were separated, as described above, by ridges formed by the fusion of thicker septa with the lamellar process uniting centers. SEM observations had revealed the presence of clusters of granules arranged over this lamellar process in a saddle-like fashion (Fig. 13H-J). 


\section{Discussion}

As a result of the evaluation above, a number of formal taxonomic actions are undertaken hereafter (Fig. 15), including the description of two new species, Micromussa pacifica sp. nov. (so far Homophyllia cf. australis) and Micromussa indiana sp. nov. (so far Micromussa cf. amakusensis), and one new genus, Australophyllia gen. nov., to accommodate $S$. wilsoni. Acanthastrea hillae is considered a junior synonym of Acanthastrea bowerbanki and this species is formally moved into Homophyllia. Finally, Montastraea multipunctata and A. lordhowensis are moved to the genus Micromussa, whereas M. minuta is moved to Acanthastrea and $M$. diminuta to Goniopora. For detailed descriptions and systematic account we refer to the Appendix. The genus Micromussa is characterized by medium tooth spacing $(0.3-1.0 \mathrm{~mm})$ and by strong, pointed and scattered septal side granulation, whereas Homophyllia shows wide tooth spacing $(>1.0 \mathrm{~mm})$ and weak, rounded, and uniformly distributed septal side granulation (Fig. 14). Conversely, Australophyllia shows medium tooth spacing $(0.3-1.0 \mathrm{~mm})$, weak, rounded, and scattered septal side granulation, and monticules.

In this study we explored the molecular phylogeny and proposed a new taxonomy for seven nominal scleractinian coral species ascribed to the Lobophylliidae (Fig. 15), corroborating the molecular data with the evaluation of the gross- and fine-scale skeleton morphology. The analyzed specimens were recovered in three main genus-level clades based on the multi-locus phylogeny reconstruction (Fig. 3) and, in particular, $M$. amakusensis, $M$. indiana sp. nov., M. pacifica, M. lordhowensis, and M. multipunctata belonged to clade A sensu Arrigoni et al. 2014a); H. australis and H. bowerbanki belonged to clade B sensu Arrigoni et al.(2014a); A. wilsoni was self-standing in a new clade. Despite these species sharing some morphological features, we showed that several macro- and micromorphological characters were diagnostic for the definition of these three genus-level lineages (Table 1). Moreover, morphological data supported molecular findings, revealing the presence of two distinct entities within H. australis (Figs 1F, 2F, 3, 9-12, S11, S12, Table 1) as well as M. amakusensis (Figs 1E, 2E, 3, 4-7, Table 1).

\section{Clade A}

The results presented in this study substantially increase the known species and macromorphological diversity of Micromussa. The genus is now composed of five species all of which are investigated in the present study, i.e. M. amakusensis, M. indiana sp. nov., $M$. lordhowensis, M. multipunctata, and M. pacifica sp. nov. (Fig. 15).

The case of $M$. indiana sp. nov. is a remarkable example of how the presumed morphological variability of a single species, M. amakusensis, over a large geographic distribution range can actually hide multiple identities. Indeed, Micromussa cf. amakusensis specimens from the Indian Ocean (Yemen) (Figs 1B, 5, 7A$\mathrm{C})$ and the typical material from the Pacific Ocean (Japan) (Figs 1A, 7D-F) were both recovered in clade A albeit in two distinct and well supported clades (Fig. 3). Although they look remarkably similar in situ, showing both a bright colouration (Figs 2B, 6 and Fig. 2A; Veron, 2000, vol. 3: 10-11, figs 1-5, respectively), and present a similar medium calice size, up to $4 \mathrm{cy}-$ cles of septa, and a similar septal spacing and micromorphology (Table 1), they can be distinguished on the basis of several macromorphological characters (Fig. 7). In the typical $M$. amakusensis, septa of the first three cycles are of equal thickness and height (Fig. 7AB) and those of the third are longer than $3 / 4$ of the first two and in most cases almost reach the columella. Conversely, in $M$. indiana sp. nov. septal length varies from slightly unequal to unequal (Fig. 5), with septa of the third (often incomplete) cycle being shorter than $1 / 2$ of those of the first two and, overall, given the more irregular corallite outline, the second to fourth cycles can be more or less complete depending on the corallite (Figs 5E-F, 7D). Finally, M. indiana sp. nov. has a smaller columella composed of less threads (Fig. 7F) than M. amakusensis (Fig. 7C). A new species of $M i$ cromussa is therefore formally described hereafter to accommodate $M$. indiana sp. nov. Therefore, the previous lack of direct comparison of skeletal morphology from Indian Ocean and Pacific Ocean material (Veron, 2000; Pichon et al., 2010) has perpetrated this error and underestimated the increasingly clear peculiarities of the Indian Ocean coral fauna (Arrigoni et al., 2012; Obura, 2012; Reijnen et al., 2014). However, once type material, specimens collected from type localities, and a large reference collection from Yemen were compared, the macromorphological differences between these species became obvious. Recent works have revealed several other cases of deep genetic divergence between Indian and Pacific populations in some species ascribed to other families, such as Blastomussa merleti (Arrigoni et al., 2012), Coelastrea aspera and C. palauensis (Huang et al., 2014b), Favites halicora (Arrigoni et al., 2012), Goniopora somaliensis (Kitano 

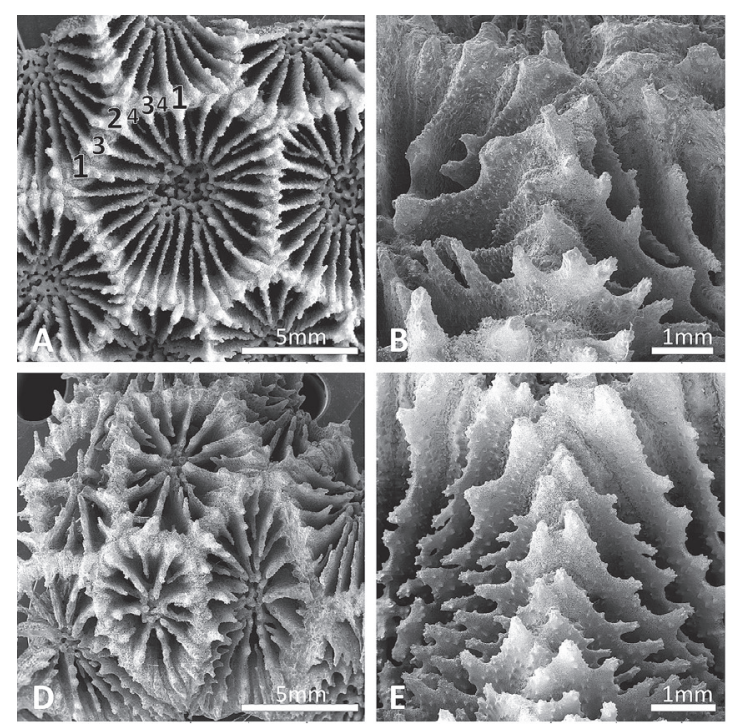

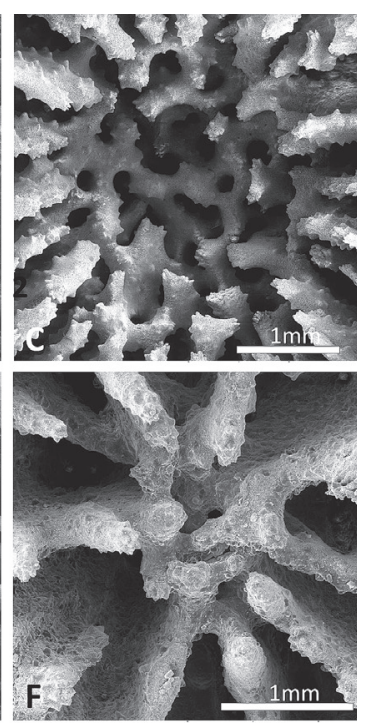

Fig. 7. Micromussa amakusensis (A-C) and Micromussa indiana sp. nov. (referred to as Micromussa cf. amakusensis in text) (D-F) compared, Scanning Electron Microscopy images. A-D) top views of calices; B-E) side view of the septa in two adjacent calices; $\mathrm{C}-\mathrm{F}$ ) top view of the columella. Arabic numerals at the outer end of the septa in A indicate the cycle number (from 1 to 4 ). et al., 2014), Pocillopora spp. (Pinzon et al., 2013), and Stylophora pistillata (Stefani et al., 2011; Keshawmurthy et al., 2011; Flot et al., 2011). Such evidence strongly argues against the concept of "geographic subspecies" proposed by Veron (1995) in order to explain the wide variety of geographic variations in some nominal species living both in the Indian and Pacific Ocean.

Micromussa lordhowensis represents one of the various cases of Acanthastrea mis-assignment highlighted by Arrigoni et al. (2014a, 2015). As shown by these authors, Acanthastrea, as interpreted until Veron (2000), was the most polyphyletic genus in the family Lobophylliidae based on mitochondrial and nuclear phylogeny reconstructions. In the present study, $M$. lordhowensis was studied for the first time from a phylogenetic perspective and transferred to Micromussa as it was found to be unrelated to the genus type, $A$. echinata (Fig. 3), but closely related to the other species in Micromussa. Furthermore, morphological analyses confirmed that $M$. lordhowensis displays the septal size, shape, and granulation typical of all Micromussa species rather than the smoother septal sides ornamentation of Acanthastrea (see also Arrigoni et al., 2015). In the original description of M. multipunctata, Hodgson (1985) stated that, despite some characteristics shared with the other species of Montastraea (now exclusively a monospecific Atlantic genus, see Budd et al. (2012)), M. multipunctata is unusual on the basis of growth form, polyp shape, and notably septal dentations. Indeed this species is also different from all the others species examined in this study due to its plocoid corallite organization. Nevertheless, the molecular results presented in this study show that M. multipunctata clearly belongs to the lineage composed of the other four Micromussa species (Fig. 3). Moreover, this species shares a similar septal teeth micromorphology with the other Micromussa species having, for example, the same type of strong septal sides and tips granulation (Fig. 12).

The other new species of Micromussa described in this study, M. pacifica sp. nov., represents a different case altogether. This solitary species has been confused for a long time with the largely sympatric Homophyllia australis (Veron and Pichon, 1980). Superficially, these two species are indeed impressively similar, especially in the field, although a closer observation of the skeletal features allowed separating them effectively, a distinction fully confirmed by the molecular results.

\section{Clade B}

The genus Homophyllia was resurrected by Budd et al. (2012) following recent morphological observations on H. australis and Parascolymia vitiensis (Budd and Stolarski, 2009). The authors demonstrated that these two Pacific species are clearly unrelated based on the septa granulation, the area between teeth, and the thickening deposits (Budd and Stolarski, 2009; Budd et al., 2012). The phylogeny reconstruction proposed in this study confirms that $H$. australis belongs to the Lobophylliidae and that it is not related to P. vitiensis (Fig. 3), thus 

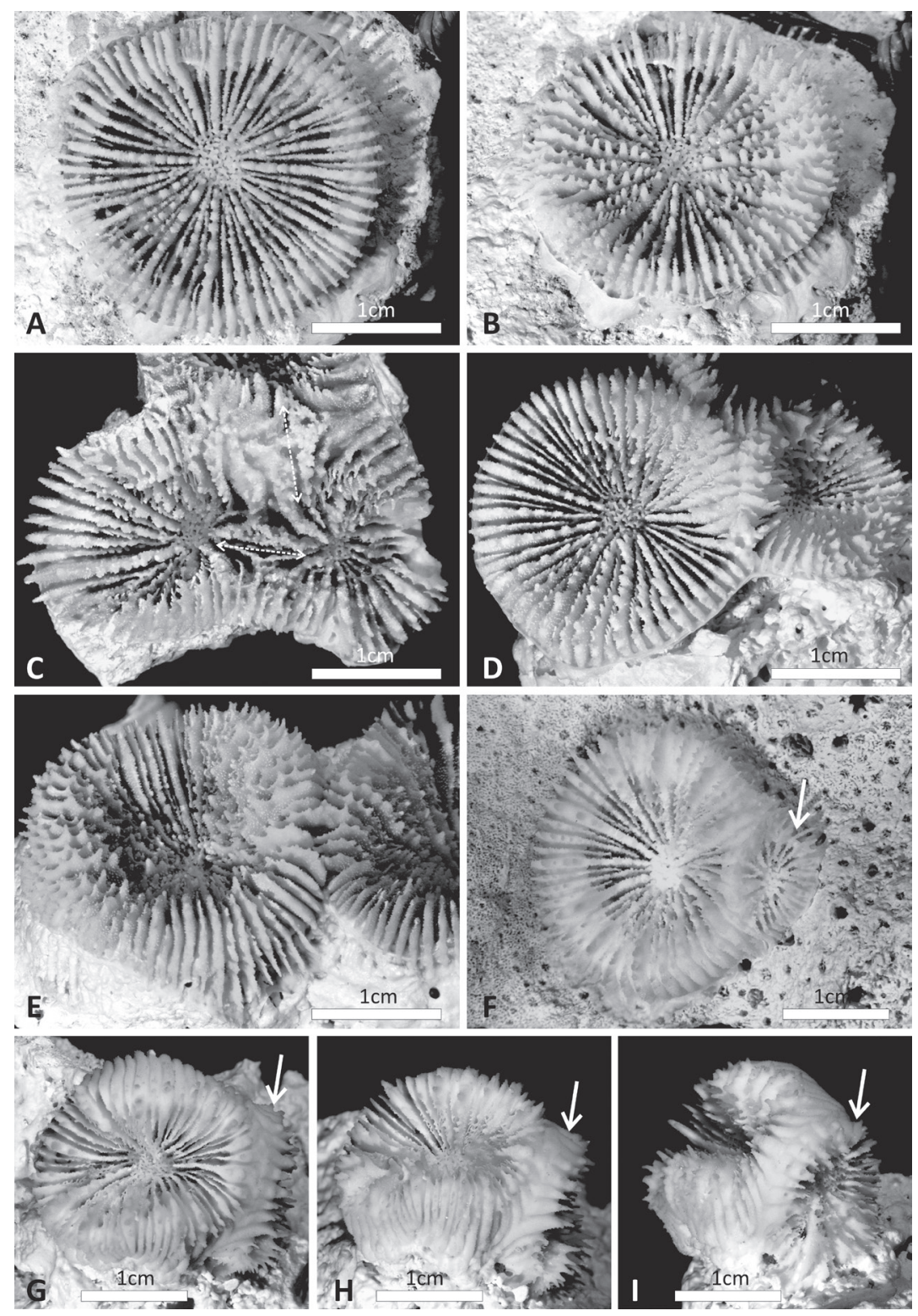

Fig. 8. Micromussa pacifica sp. nov. (referred to as Homophyllia cf. australis in text) (Specimens in A-F included in the phylogeny reconstruction in Fig. 3). A) Top and B) Side view of MNHN IK2012-16046; C) IRD HS3359 polystomatous specimen, image shows detail of the linkage (dashed line); D) MNHN IK2012-16045 polystomatous specimen; E) Side view of IRD HS3327; F) Top view of MNHN IK-2012-16043; G-I) Show top, side and lateral corallite view, respectively, of MNHN IK-2012-16044 a specimen with two calices from the Gambier Islands. White arrows indicates a budding calice. supporting the taxonomic changes proposed by Budd $e t$ al. (2012). The combination of morpho-molecular data solves a long-standing taxonomic riddle concerning the placement of these two species (Matthai, 1928; Vaughan and Wells, 1943; Wells, 1964; Veron and Pichon, 1980; Veron, 2000) and represents an excellent example of concordance between genetics and novel morphological characters (Stolarski and Roniewicz, 2001; Budd et al., 2010).

Two variable, though consistently different, morphs of the solitary species Homophyllia australis were distinguished in the examined material and the molecular analyses supported our initial separation of the large set of specimens included in our analyses in two different clades, namely the typical $H$. australis in clade B and M. pacifica sp. nov. in clade A (Fig. 3). With reference to the characters defined by Budd et al. (2012), both morphs have large calices (Figs 8, 10, $12 \mathrm{~A}, \mathrm{D})$, more than 4 cycles of septa with those of the fifth cycle or higher free (Fig. 12B, E), similar septal spacing and a trabecular and spongy columella (Figs 8, 10) of similar size relative to calice width. However, calices in $H$. australis can attain larger dimensions (Fig. S12) and reach up to 6 cycles of septa while in 

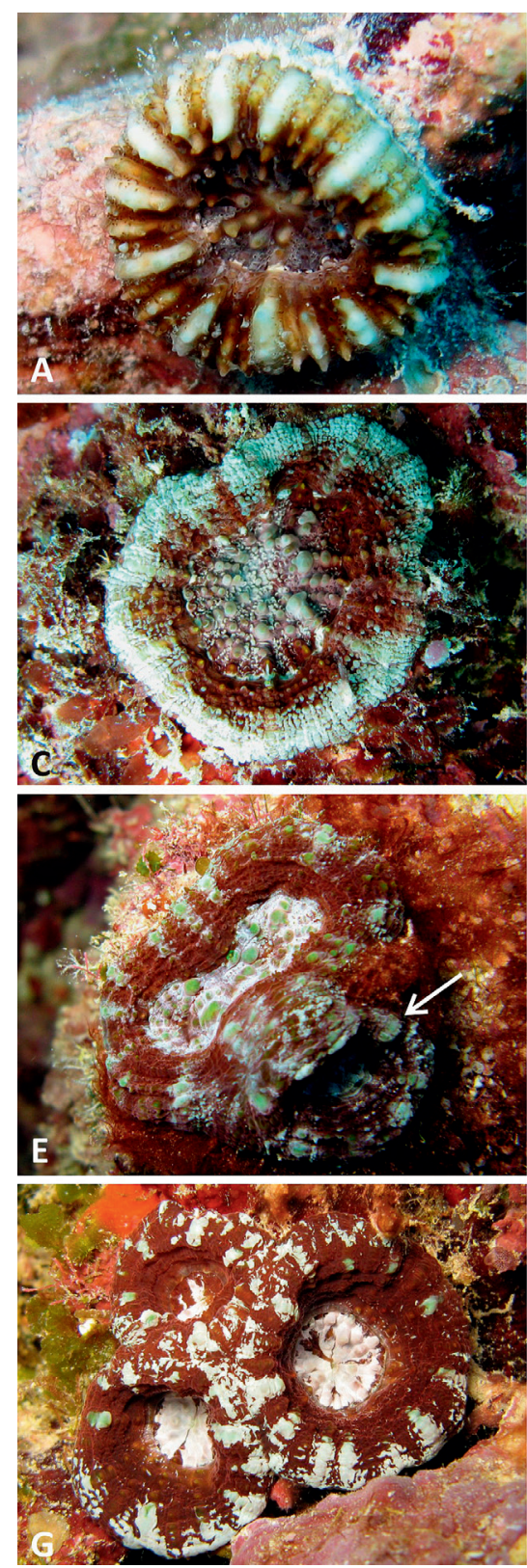
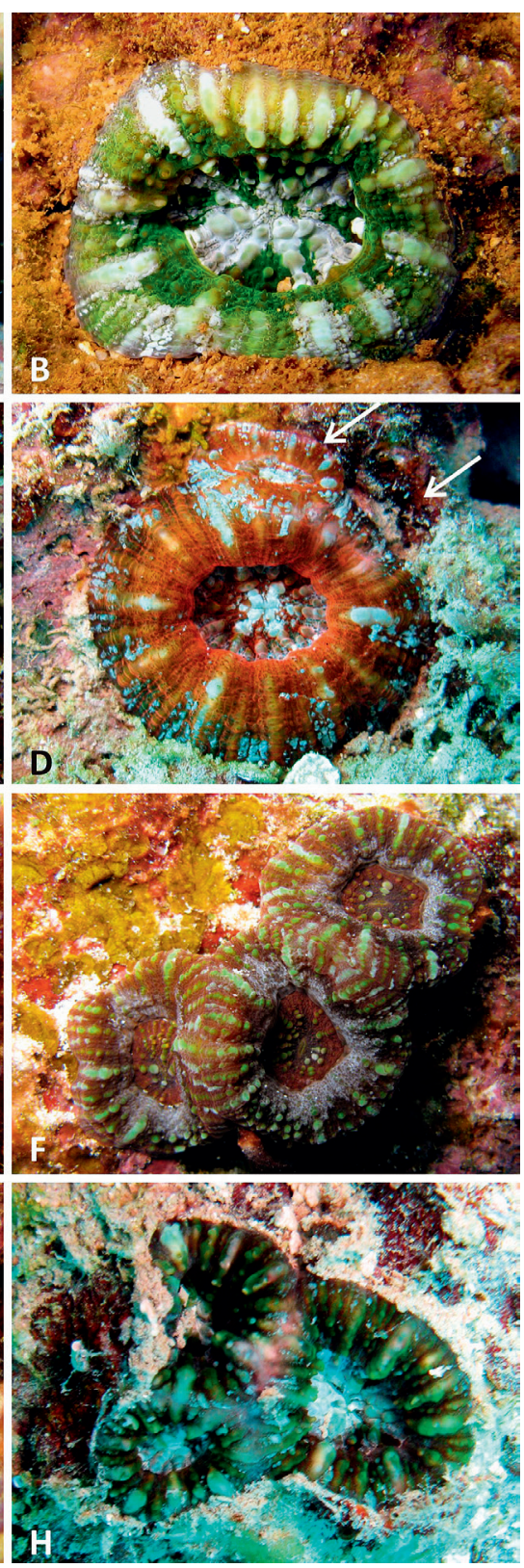

Fig. 9. Micromussa pacifica sp. nov. (referred to as Homophyllia cf. australis in text) in situ. A) Brown and white corallum with unequal septa from the lagoon pinnacles north of Mangareva Island, Gambier Islands, French Polynesia (230.12'S, $134^{\circ} 55.83^{\prime} \mathrm{W}, 05 / 07 / 2011$ ); B) IRD HS3202, green and white polyp; C) IRD HS3527, white and dark red polyp, same as in Fig. S7; D) MNHN IK2012-16043; E) IRD HS3359; F) IRD HS3327; G) IRD HS3483; H) Polystomatous colony from Taravai Island, Gambier Islands, French Polynesia (2308.72’'S; $\left.135^{\circ} 03.09^{\prime} \mathrm{W}, 08 / 07 / 2011\right)$. White arrows point at budding polyps.
M. pacifica sp. nov. the largest calices are smaller and a maximum of 5 cycles of septa were observed (Fig. S11). A more pronounced tendency to polystomatism was observed in M. pacifica sp. nov. than in the typical $H$. australis. Moreover, in H. australis septa are markedly unequal in thickness and height in all examined specimens (Figs 10, 12A-C, S12) while in M. pacifica sp. nov. septa are slightly unequal (Figs 8, 12D-F, S11) with only some cases of unequal septa observed (Figs 9A, S11), and while in the former septal teeth height increases from mid-septum towards the columella in the first two cycles, in the latter this variation is not observed. Finally, the medium septal tooth spacing and the strong, pointed and scattered septal granulation, typical of all the species recovered in clade A with Micromussa clearly distinguish $M$. pacifica sp. nov. from the typical $H$. australis having large spacing and weak, rounded, uniformly distributed granulation. The two forms co-occur in the field (e.g. in New Caledonia and in Western Australia) and their similar 

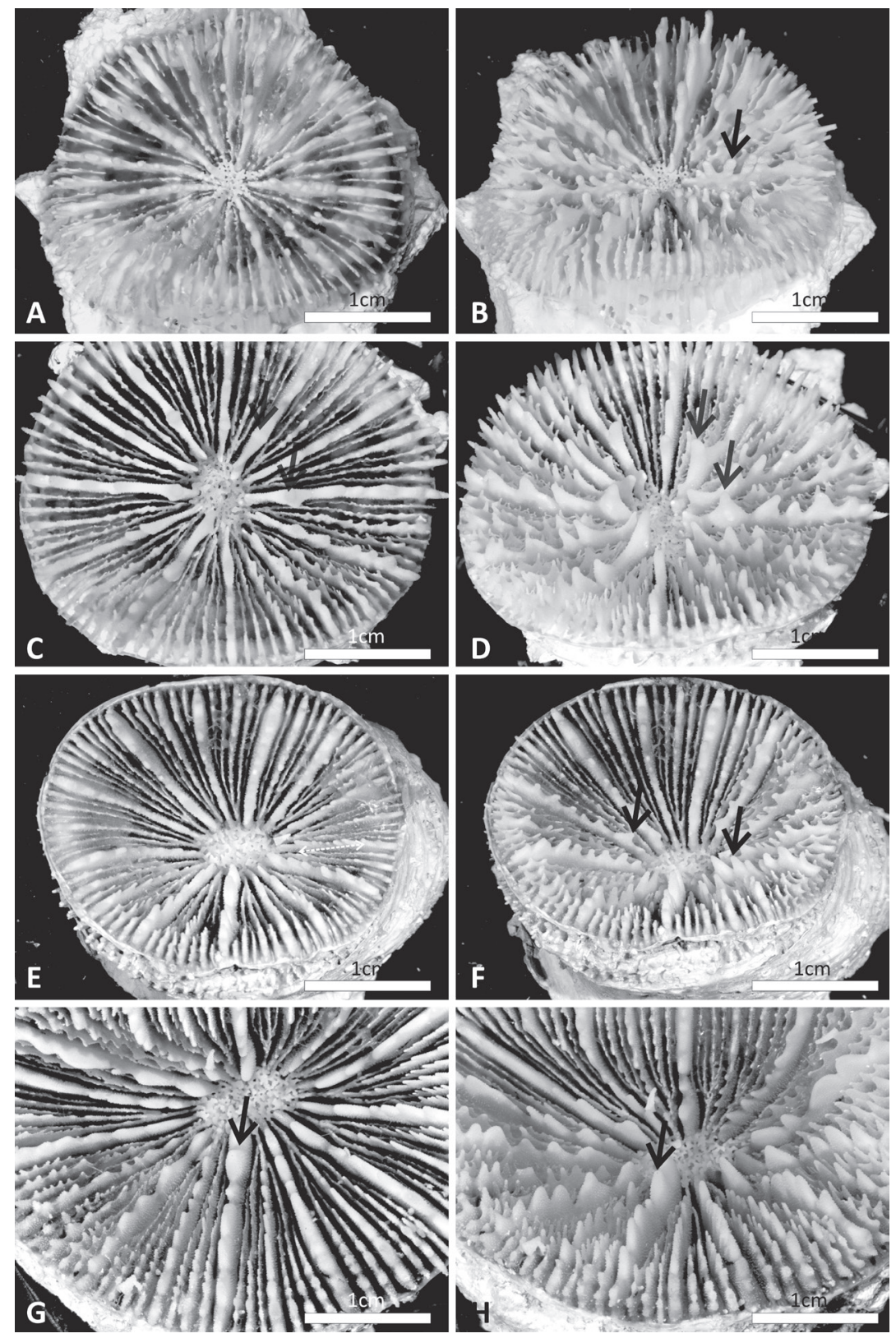

Fig. 10. Top (A, C, E, G) and side (B, D, $\mathrm{F}, \mathrm{H})$ views of Homophyllia australis (specimens included in the phylogeny reconstruction in Fig. 3. A) IRD HS3441, top view; B) Side view of the same corallum as in A; C) IRD HS3470, top view; D) Side view of the same corallum as in C; E) IRD HS3545, top view; F) Side view of the same corallum as in E; G) IRD HS3524, top view; $H$ ) side view of the same corallum as in G. Black arrows point to the large septal teeth of the first cycle of septa.

macromorphology is likely to have misled previous authors in detecting more subtle differences at the septal level. For example, Veron and Pichon (1980) included specimens of M. pacifica sp. nov. (e.g. fig. 428) and of $H$. australis (e.g. fig. 430) in the same series.

Doubts on the identification of Acanthastrea-like specimens with large polyps as Acanthastrea hillae or $H$. bowerbanki can be found in the literature. Chevalier (1975) having examined the type material of both species remarked "Acanthastrea hillae parait très proche, peut-être même identique à A. bowerbanki" (A. hillae seems very close, maybe even identical to $A$. bowerbanki). However, he also noted the differences in thickness of septa and development of septal teeth that we have also observed in our examination of the holotypes of both species despite their similar corallite size (Fig. S13A, B). Veron (2000) indicated the presence of a central larger corallite as a diagnostic character for $H$. bowerbanki but he does not mention this for A. hillae. However, the holotypes of both species 

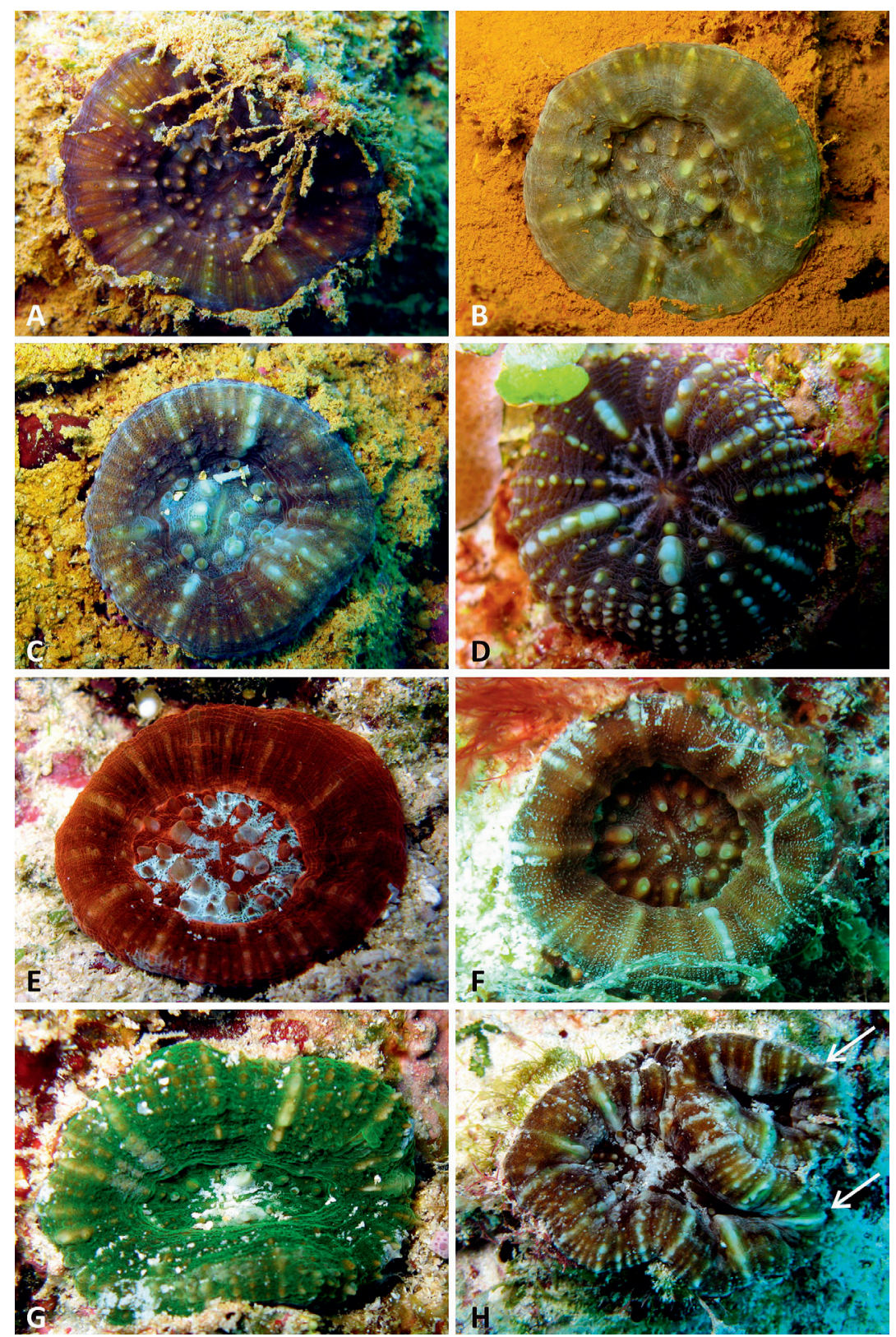

Fig. 11. Homophyllia australis in situ. A) IRD HS3544; B) IRD HS3311, same as in Figs 9 A-C; C) IRD HS3545, same as in Figs 5 E-F, S6; D) IRD HS3441, same as in Figs 5 A-B, S6; E) IRD HS3470, same as in Figs $5 \mathrm{C}-\mathrm{D}$, S6; F) IRD HS3525, same as in Fig. S6; G) IRD HS3447, same as in Fig. S6; H) IRD HS3526, polystomatous also shown in Fig. S6. have a central larger corallite undergoing intracalicular budding (Fig. S13A, B). Conversely, Veron and Pichon (1980) in their treatment of A. hillae, noted a "superficial resemblance between some coralla of this species and Moseleya latistellata which also has a central corallite, similar type of budding and corallites of similar size and shape". They further separated both species on the basis of the different septal teeth and presence of paliform lobes. In the present study we examined a large series of specimens spanning the range of the morphological variability that separates the holotypes of $H$. hillae and $A$. bowerbanki, thus including specimens with thicker (Fig. S13C) and thinner (Fig. S13D) septa, as well as specimens with more obvious larger central corallites (Fig. S13D) and lack thereof (Fig. S13E). All these were recovered in the same well-supported clade in clade B (Fig. 3) and no differences in any of the morphological characters considered (other than relative costosepta thickness) were observed. We conclude that in absence of evi- 

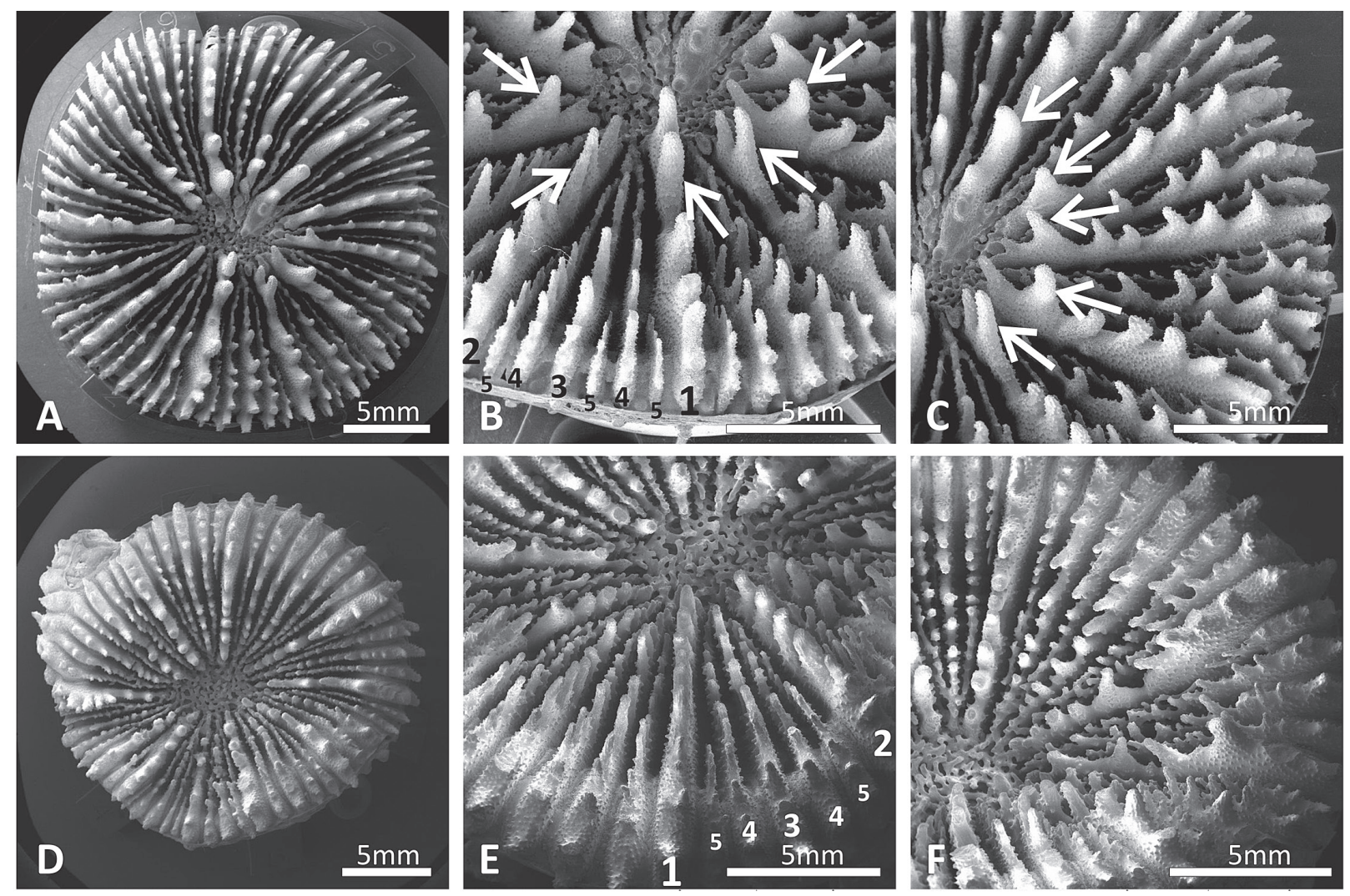

Fig. 12. Homophyllia australis (IRD HS3311; A-C) and Micromussa pacifica sp. nov. (referred to as Homophyllia cf. australis in text) (D-F) compared, Scanning Electron Microscopy images. A-D) top views of calices; B-E) enlarged side view of the calice; C-F) side view of septa. Arabic numerals at the outer end of the septa in B and E indicate the cycle number (from 1 to 5). White arrows point at the larger septal tooth present at the inner end of septa in typical Homophyllia australis.

dence of morphological and molecular characters that allow the separation of the two nominal species, $H$. bowerbanki is a senior synonym of A. hillae, and therefeore has preference. Furthermore, based on the placement of this species in clade B together with $H$. australis, rather than in clade $\mathrm{E}$ with the type species of Acanthastrea, and the consistent micromorphological affinities between the two species (Table 1), we formally move A. hillae into the genus Homophyllia as a junior synonym of $H$. bowerbanki.

As a result of the morphological and molecular investigations presented in this study, the once monospecific genus Homophyllia now includes two species, $H$. australis, the predominantly solitary type species, and the colonial H. bowerbanki (Fig. 15). Although previous authors noted the pronounced septal sides granulation of both species (Veron and Pichon, 1980), the strikingly different corallum shape likely kept them from considering this skeletal feature as phylogenetically informative, thus solitary and colonial species were maintained in different genera. A similar situation has also been recently reported for another lobophylliid genus, Sclerophyllia, originally consisting of a monostomatous species (Klunzinger, 1879). The genus was recently revised based on molecular and morphological evidence and is currently composed of a solitary and a colonial species (Arrigoni et al., 2015). This result is not entirely unexpected, because in the scleractinian family Fungiidae, monostomatous and polystomatous species were traditionally also classified in different genera despite close phylogenetic relations (Hoeksema 1989, 1991, 1993). Molecular analyses have resulted in a new classification of this family, in which this distinction does not matter anymore, such as among species of the genera Cycloseris and Pleuractis (Gittenberger et al., 2011; Benzoni et al., 2012).

Despite superficial macromorphological similarities between $H$. bowerbanki and Acanthastrea species, mainly the size and arrangement of corallites and the number of septa (Veron and Pichon, 1980), consistent 

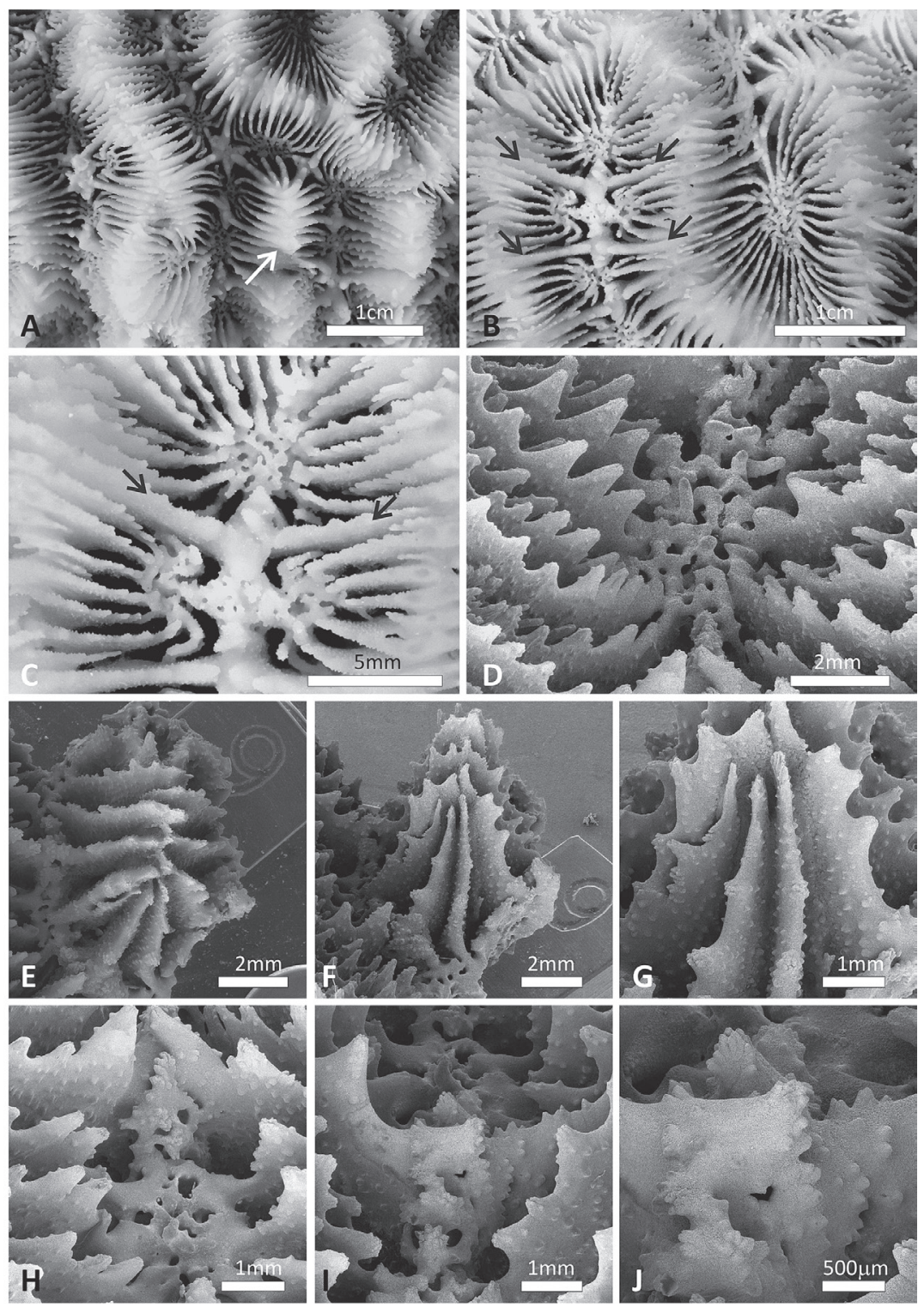
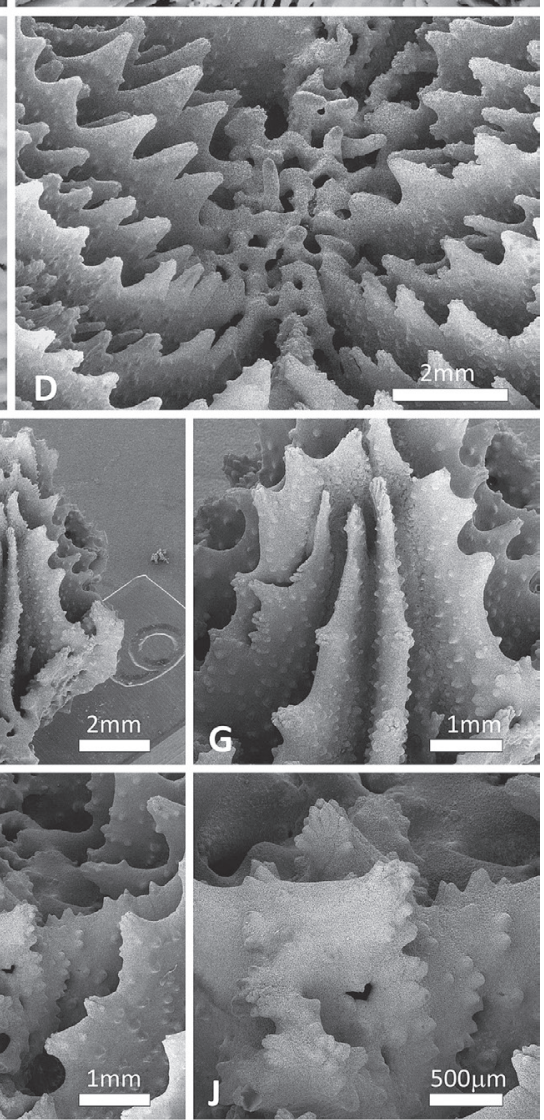

Fig. 13. Australophyllia wilsoni (previously Symphyllia) AM WIL1. A) meandering valleys and a hydnophoroid formation (white arrow) which can be found in this species; B) Full sized corallite on the left hand side, side by side with a valley in which the centers have an unusual morphology and thicker septa (black arrows) seem to separate the columellae, which are also almost split in two; C) A close up of the columellae shown in B; D) SEM of the columella sitting deep in the valleys; E) SEM top view of a hydnophoroid formation; F) SEM side view of the same hydnophoroid formation as in E; G) Close up of F showing septal side granulation; H) In the foreground a columella and in the background behind it the thicker septa separating ad jacent columellae indicated by the black arrows in $\mathrm{B}$ and $\mathrm{C}$; I) A detail of the peculiar structure forming saddle-shaped structure on the two adjoining inner ends of the thicker septa separating adjacent columellae; J) Granulation of the saddleshaped structure shown in I. differences in septal tooth micromorphology were evidenced between these species (Budd and Stolarski, 2009; Arrigoni et al., 2015). Furthermore, a deep genetic divergence separates the clade including $H$. bowerbanki from the lineage leading to the species of Acanthastrea (Fig. 3; Arrigoni et al., 2014a, 2014b, 2015). Indeed, some large specimens of Acanthastrea, like the colonies of $A$. hemprichii included in molecular and morphological analyses of the present study (Figs 1J, 2J), can look similar to $H$. bowerbanki and A. hillae (Figs 1G-H, 2G-H) and were therefore preliminarily identified as such in the field. However, none of the specimens from the Indian Ocean identified as A. hillae in the present study actually belong to A. hillae. Thus, it is possible that the supposed presence of this species in the Indian Ocean (Veron, 2000) is actually derived from erroneous identifications of A. hemprichii. Veron (2000, vol. 3, p. 28) himself reports that "records from the western Indian Ocean are doubtful". If this is the case, the geographic distribution of the genus Homophyllia would be restricted to the western Pacific, encompassing tropical, sub-tropical, and temperate conditions. Moreover, the two species of Homophyllia are predominantly sub-tropical, being uncommon within 

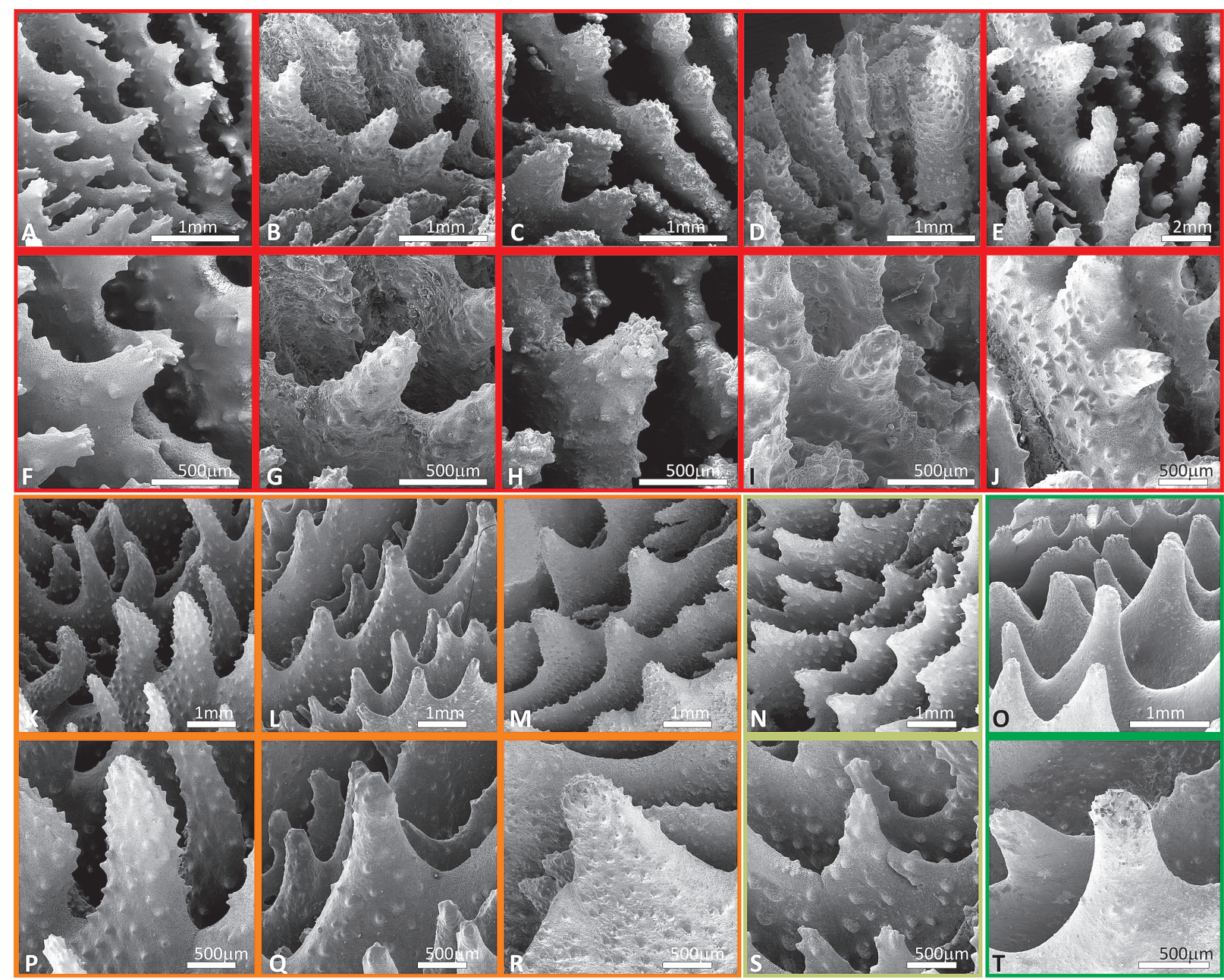

Fig. 14. Scanning Electron Microscopy images of the septal teeth (A-E, K-O) and granules (F-J, P-T) of the examined Lobophylliidae recovered in clade A (A-J), clade B (K-M, P-R), clade J (N, S), clade E (O, T) (see Fig. 3 for clades and colour codes). A, F) Micromussa amakusensis; B, G) Micromussa indiana sp. nov. (referred to as Micromussa cf. amakusensis in text); C, H) Micromussa lordhowensis (previously Acanthastrea) AM 1642; D, I) Micromussa multipunctata (previously Montastraea) RMNH Coel 40090; E, J) Micromussa pacifica sp. nov. (referred to as Homophyllia cf. australis in text);K, P) Homophyllia australis IRD HS3311; L, Q) Homophyllia bowerbanki (previously Acanthastrea) AM 4629; M, R) Homophyllia bowerbanki (previously A. hillae) AM MH019; N, S) Australophyllia wilsoni (previously Symphyllia) AM WIL1; O, T) Acanthastrea cf. hemprichii (referred in the text as A. cf. hillae) UNIMIB BA115.

their range but relatively frequent in sub-tropical localities, such as Japan, New Caledonia, and south-western Australia (Veron and Marsh, 1988; Veron, 1993, 2000; Wallace et al., 2009). For example, in Australia they are rare on the Great Barrier Reef but are relatively common south to Moreton Bay (Veron and Pichon, 1980; Veron and Marsh, 1988; Wallace et al., 2009).

\section{Clade J}

The most unexpected result of the present study is the recovery of Australophyllia wilsoni, formerly assigned to Symphyllia, as a distinct lineage within the Lobophylliidae. The multi-locus phylogeny reconstruction and each of the three single gene topologies are concordant in supporting this unique assignment although the best resolution is obtained using the concatenated data set (Figs 3, S3-S6). Considering the concatenated COI-histone H3-ITS region data set, the interclade genetic distances between A. wilsoni and the other eight clades go from the smallest values with clade A $(3.2 \pm 0.4 \%)$ and clade B $(3 \pm 0.4 \%)$ to the largest one with clade $\mathrm{G}(9.6 \pm 0.7 \%)(\mathrm{S} 2)$, while all of the other distances vary between 5.6 and 6.2. These 


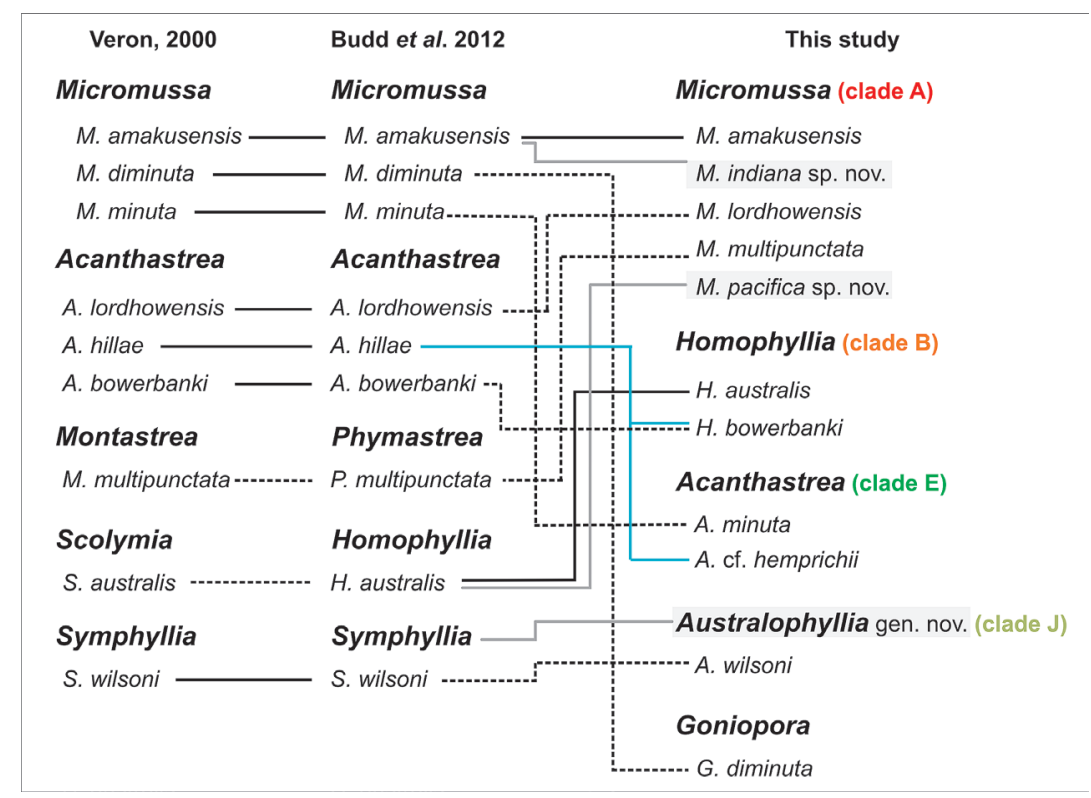

Fig. 15. Recent changes in classification of the taxa analyzed in this study. Black lines indicate no changes, dashed black lines indicate movements of species among genera, light blue lines indicate synonymies, and grey lines indicate to which taxon the known material of the new taxa described in this study (highlighted in grey) had been previously assigned to. distances completely overlap with the pairwise interclade distances for the other clades, thus confirming the genetic distinctiveness of $A$. wilsoni within its family.

In the original description of $A$. wilsoni, Veron (1985) placed the species in the genus Symphyllia considering the massive or sub-massive flattened colony and a general resemblance of the meandroid corallite arrangement to that of this genus, although corallites are smaller than those of any other Symphyllia species (Veron, 2000). Despite a superficial appearance of the macromorphology of the colony to some merulinds, such as Platygyra and Oulophyllia, Veron (1985) included A. wilsoni within the Mussidae (now an exclusively Atlantic taxon, see Budd et al. (2012)) because of the size of septal dentations and the thick and fleshy aspect of living polyps. Our molecular analyses demonstrate that the species belongs to the Lobophylliidae but that it is not closely related to any of the known extant lobophylliid genera, showing a sister relationship with the group composed by Micromussa and Homophyllia (Fig. 3). These genetic findings are also supported by a combination of several macro and micromorphological characters illustrating the uniqueness of $A$. wilsoni among the other taxa examined in the present study (Table 1), and among the lobophylliids in general, also due to the presence of monticules and the morphology of the columella in series of calices.

Another interesting feature of A. wilsoni is represented by its geographic distribution. The species is restricted to the temperate waters of south-west Aus- tralia, recorded from Shark Bay to Geographe Bay along the coasts of Western Australia and thence east to Bremer Bay in south Australia (Veron, 1985, 1993, 2000; Veron and Marsh, 1988). It is usually found in shallow water on kelp-dominated coastal exposed rock surfaces (Veron, 1985, 1993; Veron and Marsh, 1988). This peculiar distribution range mostly overlaps that of another distinctive species, Coscinaraea marshae, and it is also similar to that of the south-eastern Australian species Coscinaraea mcneilli, otherwise it is unlike that of any other known extant coral species (Veron and Pichon, 1980; Veron and Marsh, 1988; Veron, 1993, 2000).

\section{Taxa outside clades $A, B$, and $J$}

For Goniopora diminuta and Acanthastrea minuta, no molecular and micromorphological data are available and, to our knowledge, few specimens are deposited at museums. We examined the lectoype of the former species and the holotype of the latter one (Fig. S15). The present macromorphological observations allowed us to clarify that neither species actually belongs to Micromussa.

The lectotype of G. diminuta (MTQ G 55851, Veron, 2002, figs 235-237, Fig. S15A, B, D) is in fact a specimen of the poritid genus Goniopora, most likely a G. somaliensis. The corallites in this specimen show the typical septal structure and fusion of the genus $\mathrm{Go}$ niopora Blainville, 1830, a columella made of a single 
vertical process and the presence of five pali around it (Fig. S15B). Moreover, the observation of the skeletal structure in longitudinal section shows the typical porous mesh of trabeculae and synapticulae observed in poritiids (Fig. S15D). The size of the calices $(3-4$ $\mathrm{mm}$ ) and the pattern of septal fusion resemble those observed in the holotype of Goniopora somaliensis Vaughan, 1907 (Fig. S15C). In situ images of this species in Veron (2000, vol. 39, figs 2-4) show, as also remarked by the author, a lack of the "thick fleshy tissue over the skeleton" typical of the lobophylliids. However, as no image showing the appearance of the holotype before collection was published it cannot be ascertained if these images actually correspond to the same specimen. On the basis of the skeletal morphology described above, this species is, therefore in the present revision not included in the genus Micromussa but in the genus Goniopora.

The holotype of Acanthastrea minuta (Moll \& Best, 1984, RMNH Coel. 15275, Fig. S15E, F) shows all the characters of the genus Acanthastrea, to which it is restored, rather than those of Micromussa and thus it is not included in Micromussa in the present study. This specimen has a well-developed spinose coenosteum, less than six septa per $5 \mathrm{~mm}$ in terms of septal spacing, and less than six teeth per septum (Fig. S15F). Veron (2000) moved this species to the genus Micromussa likely due to the small diameter of the calices. However, the image of the skeleton published by Veron (2000, vol. 3: 8) shows a specimen with a different morphology from that of the holotype with very unequal costosepta in relative thickness. On the basis of these observations the species is returned to the genus Acanthastrea.

The material from the Indian Ocean identified as Acanthastrea cf. hillae on the basis of macromorphology (Figs $1 \mathrm{H}, 2 \mathrm{H}$ ) was recovered in clade $\mathrm{E}$ together with all the Acanthastrea species, including the genus type species (Fig. 3). Despite a similar macromorphology to A. hillae and H. bowerbanki for all the characters examined in this study, including the size of calices and the number of septa (Table 1), the SEM observations allowed us to ascertain that septal granulation in the examined material is weak, rounded, enveloped by thickening deposits and, thus, different from that of all the species recovered in clades A and B (Fig. 14O, T). This suggests that Acanthastrea specimens with large calices may indeed have been previously misidentified as A. hillae as in the case of the specimen shown by Veron $\&$ Pichon (1980, figs 442 and 444). As no specimens of $A$. hillae have been collected in the Indian Ocean so far, either for this study or in the examined museum collections (namely at the MTQ, MNHN, or RMNH), the records for this species outside the Pacific Ocean are considered dubious and might be referred as $A$. cf. hemprichii until further morpho-molecular studies will clarify their status.

\section{Final remarks}

A growing volume of work dealing with taxonomy and systematics of scleractinian corals have demonstrated that the use of both genetic and morphological analyses is an indispensable approach to understand and clarify the evolution of these invertebrates (Benzoni et al., 2007, 2010, 2012a, 2012b; Budd et al., 2010, 2012; Gittenberger et al., 2011; Stolarski et al., 2011; Kitahara et al., 2012a, 2012b; Schmidt-Roach et al., 2014; Huang et al., 2014b; Arrigoni et al., 2014c; Terraneo et al., 2014). In this study we combine robust molecular analyses based on multiple DNA regions with detailed observations of morphology at colony, corallite, and sub-corallite scales. The present work increases the current knowledge of taxonomy and biodiversity of the family Lobophylliidae and, more generally, highlights the importance of analyzing both genetics and morphology. The inclusion of as many species as possible and from different localities, as done here for M. amakusensis, in a molecular phylogenetic framework is a necessary step towards a comprehensive reconstruction of coral evolutionary history as an increasing number of previously unstudied taxa exhibit unexpected phylogenetic placements that have been misunderstood and ignored by traditional systematics (Fukami et al., 2004a, 2008; Kitahara et al., 2010, 2012a, 2012b; Stolarski et al., 2011; Huang et al., 2011, 2014b; Arrigoni et al., 2014a; Kitano et al., 2014). We strongly encourage the examination of specimens from multiple localities, ideally including the entire geographic distribution range of a species and above all the type locality, in order to define the intraspecific morphological variation and evaluate the possible presence of cryptic or previously overlooked species. Finally, we recommend also the inclusion of microstructural data to the presented molecular and micromorphological observations in future works as they were demonstrated to be useful and diagnostic in previous systematic revisions (Budd et al., 2012; Kitahara et al., 2012b; Huang et al., 2014a: Arrigoni et al., 2014c; Janiszewska et al., 2015). 


\section{Acknowledgements}

New Caledonia data and specimens were obtained during the CORALCAL4 (http://dx.doi.org/10.17600/12100060), BIBELOT (http://dx.doi.org/10.17600/14003700), CORALCAL5 (http://dx.doi.org/10.17600/15004300), and CHEST (http://dx. doi.org/10.17600/15004500) expeditions on the RV Alis. We are grateful to the Captain and the crew for their valuable help during the campaigns and their knowledge of the Neocaledonian reefs during fieldwork. The participation of F.B. and B.W.H. was possible thanks to the kind help and support of C. Payri and B. Dreyfus. We are also grateful to J.L. Menou, J. Butscher, G. Lasne, E. Folcher, and A. Arnaud. We are grateful to E. Karsenti (EMBL), É. Bourgois (Tara Expeditions), and the OCEANS Consortium for sampling in Gambier Island during the Tara Oceans expedition. We thank the commitment of the following people and sponsors who made this singular expedition possible: CNRS, EMBL, Genoscope/CEA, VIB, Stazione Zoologica Anton Dohrn, UNIMIB, ANR (projects POSEIDON/ANR-09BLAN-0348, BIOMARKS/ANR-08-BDVA-003, PROMETHEUS/ANR-09-GENM-031, and TARA-GIRUS/ ANR09-PCS-GENM-218), EU FP7 (MicroB3/No.287589), FWO, BIO5, Biosphere 2, agnès b., the Veolia Environment Foundation, Region Bretagne, World Courier, Illumina, Cap L'Orient, the EDF Foundation EDF Diversiterre, FRB, the Prince Albert II de Monaco Foundation, Etienne Bourgois, and the Tara schooner along with its captain and crew. Tara Oceans would not exist without continuous support from 23 institutes (http://oceans.taraexpeditions.org). This article is contribution number 44 of the Tara Oceans Expedition 2009-2012. We are grateful to E. Dutrieux (CREOCEAN), C.H. Chaineau (Total SA), R. Hirst, and M. AbdulAziz for allowing and supporting research in Yemen. We thank M. Pichon, S. Basheen, M.A. Ahmad, A. Suliman, F.N. Saeed, C. Riva, S. Montano, and A. Caragnano for their help in various aspects of field work in Yemen. T.H. Synclair-Taylor is acknowledged for (the best) in situ images of Homophyllia from Lord Howe Island, Australia. We are grateful to J. Moore for providing images of type material from the USNM. Coral collecting by B.W.H. was done during the Tun Mustapha Park Expedition 2012, which was jointly-organized by WWF Malaysia, Universiti Malaysia Sabah, Sabah Parks (Malaysia) and Naturalis Biodiversity Center, with special thanks to $\mathrm{Z}$. Waheed who arranged the research permits. Coral collecting by A.H.B. was funded by the ARC Centre of Excellence for Coral Reef Studies. We are grateful to P. Gentile for technical help with SEM and P. Galli for laboratory support at UNIMIB. R.A. gratefully acknowledges the National Science Council of Taiwan for Summer Program in Taiwan 2013. This work is supported by King Abdullah University of Science and Technology's Red Sea Research Center (CCF. grant FCC/1/1973-07 to M.L.B.).

\section{References}

Arrigoni R, Berumen ML, Terraneo TI, Caragnano A, Bouwmeester J, Benzoni F. 2015. Forgotten in the taxonomic literature: resurrection of the scleractinian coral genus Sclerophyllia (Scleractinia, Lobophylliidae) from the Arabian Peninsula and its phylogenetic relationships. Systematics and Biodiversity 49: 140-163.
Arrigoni R, Kitano YF, Stolarski J, Hoeksema BW, Fukami H, Stefani F, Galli P, Montano S, Castoldi E, Benzoni F. 2014c. A phylogeny reconstruction of the Dendrophylliidae (Cnidaria, Scleractinia) based on molecular and micromorphogical criteria, and its ecological implications. Zoologica Scripta 43: 661-688.

Arrigoni R, Richards ZT, Chen CA, Baird AH, Benzoni F. 2014b. Phylogenetic relationships and taxonomy of the coral genera Australomussa and Parascolymia (Scleractinia, Lobophylliidae). Contributions to Zoology 83: 195-215.

Arrigoni R, Stefani F, Pichon M, Galli P, Benzoni F. 2012. Molecular phylogeny of the Robust clade (Faviidae, Mussidae, Merulinidae, and Pectiniidae): An Indian Ocean perspective. Molecular Phylogenetics and Evolution 65: 183193.

Arrigoni R, Terraneo TI, Galli P, Benzoni F. 2014a. Lobophylliidae (Cnidaria, Scleractinia) reshuffled: pervasive nonmonophyly at genus level. Molecular Phylogenetics and Evolution 73: 60-64.

Arrigoni R, Vacherie B, Benzoni F, Barbe V. 2016. The complete mitochondrial genome of Acanthastrea maxima (Cnidaria, Scleractinia, Lobophylliidae). Mitochondrial DNA 27: 927-928.

Bandelt HJ, Forster P, Röhl A. 1999. Median-joining networks for inferring intraspecific phylogenies. Molecular Biology and Evolution 16: 37-48.

Benzoni F. 2013. Echinophyllia tarae sp. n. (Cnidaria, Anthozoa, Scleractinia), a new reef coral species from the Gambier Islands, French Polynesia. ZooKeys 318: 59-79.

Benzoni F, Arrigoni R, Stefani F, Pichon M. 2011. Phylogeny of the coral genus Plesiastrea (Cnidaria, Scleractinia). Contributions to Zoology 80: 231-249.

Benzoni F, Arrigoni R, Stefani F, Stolarski J. 2012a. Systematics of the coral genus Craterastrea (Cnidaria, Anthozoa, Scleractinia) and description of a new family through combined morphological and molecular analyses. Systematics and Biodiversity 10: 417-433.

Benzoni F, Arrigoni R, Stefani F, Reijnen BT, Montano S, Hoeksema BW. 2012b. Phylogenetic position and taxonomy of Cycloseris explanulata and C. wellsi (Scleractinia: Fungiidae): lost mushroom corals find their way home. Contributions to Zoology 81: 125-146.

Benzoni F, Arrigoni R, Waheed Z, Stefani, F, Hoeksema BW. 2014. Phylogenetic relationships and revision of the genus Blastomussa (Cnidaria: Anthozoa: Scleractinia) with description of a new species. The Raffles Bullettin of Zoology 62: $358-378$

Benzoni F, Stefani F, Pichon M, Galli P. 2010. The name game: morpho-molecular species boundaries in the genus Psammocora (Cnidaria, Scleractinia). Zoological Journal of the Linnean Society 160: 421-456.

Benzoni F, Stefani F, Stolarski J, Pichon M, Mitta G, Galli P. 2007. Debating phylogenetic relationships of the scleractinian Psammocora: molecular and morphological evidences. Contributions to Zoology 76: 35-54.

Budd AF, Stolarski J. 2009. Searching for new morphological characters in the systematics of scleractinian reef corals: comparison of septal teeth and granules between Atlantic and Pacific Mussidae. Acta Zoologica 90: 142-165.

Budd AF, Fukami H, Smith N, Knowlton N. 2012. Taxonomic classification of the reef coral family Mussidae (Cnidaria: 
Anthozoa: Scleractinia). Zoological Journal of the Linnean Society 166: 465-529.

Budd AF, Romano SL, Smith ND, Barbeitos MS. 2010. Rethinking the phylogeny of Scleractinian corals: a review of morphological and molecular data. Integrative and Comparative Biology 50: 411-427.

Budd AF, Stolarski J. 2011. Corallite wall and septal microstructure in scleractinian reef corals: comparison of molecular clades within the family Faviidae. Journal of Morphology 272: 66-88.

Chevalier JP. 1975. Les Scléractiniaires de la Mélanésie Française (Nouvelle-Calédonie, Iles Chesterfield, Iles Loyauté, Nouvelles Hébrides). Expédition Francaise Sur les Récifs Coralliens de la Nouvelle-Calédonie, Deuxieme Partie 7: 1-407.

Colgan DJ, McLauchlan A, Wilson GDF, Livingston SP, Edgecombe GD, Macaranas J, Gray MR. 1998. Histone H3 and U2 snRNA DNA sequences and arthropod molecular evolution. Australian Journal of Zoology 46: 419-437.

Dai CF, Horng S. 2009. Scleractinia fauna of Taiwan II. The robust group. Taipei: National Taiwan University.

Flot JF, Blanchot J, Charpy L, Cruaud C, Licuanan WY, Nakano Y, Payri C, Tillier S. 2011. Incongruence between morphotypes and genetically delimited species in the coral genus Stylophora: phenotypic plasticity, morphological convergence, morphological stasis or interspecific hybridization? BMC Ecology 11: 22.

Fukami H, Budd AF, Levitan DR, Jara J, Kersanach R, Knowlton N. 2004b. Geographic differences in species boundaries among members of the Montastraea annularis complex based on molecular and morphological markers. Evolution 58: 324-337.

Fukami H, Budd AF, Paulay G, Sole-Cava A, Chen CA, Iwao, K, Knowlton N. 2004a. Conventional taxonomy obscures deep divergence between Pacific and Atlantic corals. Nature 427: 832-835.

Fukami H, Chen CA, Budd AF, Collins A, Wallace C, Chuang YY, Chen C, Dai CF, Iwao K, Sheppard C, Knowlton N. 2008. Mitochondrial and nuclear genes suggest that stony corals are monophyletic but most families of stony corals are not (Order Scleractinia, Class Anthozoa, Phylum Cnidaria). PLoS ONE 3: e3222.

Gittenberger A, Reijnen BT, Hoeksema BW. 2011. A molecularly based phylogeny reconstruction of mushroom corals (Scleractinia: Fungiidae) with taxonomic consequences and evolutionary implications for life history traits. Contributions to Zoology 80: 107-132.

Guindon S, Gascuel O. 2003. A simple, fast, and accurate algorithm to estimate large phylogenies by maximum likelihood. Systematic Biology 52: 696-704.

Hodgson G, Carpenter K. 1995. Scleractinian corals of Kuwait. Pacific Science 49: 227-246.

Hoeksema BW. 1989. Taxonomy, phylogeny and biogeography of mushroom corals (Scleractinia: Fungiidae). Zoologische Verhandelingen 254: 1-295.

Hoeksema BW. 1991. Evolution of body size in mushroom corals (Scleractinia: Fungiidae) and its ecomorphological consequences. Netherlands Journal of Zoology 41: 122-139.

Hoeksema BW. 1993. Historical biogeography of Fungia (Pleuractis) spp. (Scleractinia: Fungiidae), including a new species from the Seychelles). Zoologische Mededelingen 67: 639-654.
Hoogenboom MO, Frank GE, Blowes SA, Chase TJ, Zawada KJA, Dornelas M. 2015. Disparity between projected geographic ranges of rare species: a case study of Echinomorpha nishihirai (Scleractinia). Marine Biodiversity Records 8: e147.

Huang D, Benzoni F, Fukami H, Knowlton N, Smith ND, Budd AF. 2014a. Taxonomic classification of the reef coral families Merulinidae, Montastraeidae, and Diploastraeidae (Cnidaria: Anthozoa: Scleractinia). Zoological Journal of the Linnean Society 171: 277-355.

Huang D, Benzoni F, Arrigoni R, Baird AH, Berumen ML, Bouwmeester J, Chou LM, Fukami H, Licuanan WY, Lovell ER, Meier R, Todd PA, Budd AF. 2014b. Towards a phylogenetic classification of reef corals: the Indo-Pacific genera Merulina, Goniastrea and Scapophyllia (Scleractinia, Merulinidae). Zoologica Scripta 43: 531-548.

Huang D, Licuanan WY, Baird AH, Fukami H. 2011. Cleaning up the "Bigmessidae": molecular phylogeny of scleractinian corals from Faviidae, Merulinidae, Pectiniidae, and Trachyphylliidae. BMC Evoutionary Biology 11: 37.

Huang D, Meier R, Todd PA, Chou LM. 2009. More evidence for pervasive paraphyly in scleractinian corals: systematic study of Southeast Asian Faviidae (Cnidaria; Scleractinia) based on molecular and morphological data. Molecular Phylogenetics and Evolution 50: 102-116.

Huelsenbeck JP, Ronquist F. 2001. MRBAYES: Bayesian inference of phylogenetic trees. Bioinformatics 17: 754-755.

Janiszewska K, Jaroszewcz J, Stolarski J. 2013. Skeletal ontogeny in basal scleractinian micrabaciid morals. Journal of Morphology 274: 243-257.

Janiszewska K, Stolarski J, Benzerara K, Meibom A, Mazur M, Kitahara MV, Cairns SD. 2011. A unique skeletal microstructure of the deep-sea micrabaciid scleractinian corals. Journal of Morphology 231: 191-203.

Janiszewska K, Stolarski J, Kitahara MV, Neuser ND, Mazur M. 2015. Microstructural disparity between basal micrabaciids and other Scleractinia: new evidence from Neogene Stephanophyllia. Lethaia. doi: 10.1111/let.12119

Katoh K, Standley DM. 2013. MAFFT multiple sequence alignment software version 7: improvements in performance and usability. Molecular Biology and Evolution 30: 772-780.

Katoh K, Misawa K, Kuma K, Miyata T. 2002. MAFFT: a novel method for rapid multiple sequence alignment based on fast Fourier transform. Nucleic Acids Resourches 30: 30593066.

Keshavmurthy S, Yang SY, Alamaru A, Chuang YY, Pichon M, Obura DO, Fontana S, De Palmas S, Stefani F, Benzoni F, Mac-Donald A, Noreen AME, Chen C, Wallace CC, Pillay R, Denis V, Amri AY, Reimer JD, Mezaki T, Sheppard C, Loya Y, Abelson A, Mohammed MS, Baker AC, Mostafavi PG, Suharsono BA, Chen CA. 2013. DNA barcoding reveals the coral "laboratory-rat", Stylophora pistillata encompasses multiple identities. Scientific Reports 3: 1520.

Kitahara MV, Cairns SD, Stolarski J, Miller DJ. 2012a. Deltocyathiidae, an early-diverging family of Robust corals (Anthozoa, Scleractinia). Zoologica Scripta 42: 201-212.

Kitahara MV, Cairns SD, Stolarski J, Blair D, Miller DJ. 2010. A comprehensive phylogenetic analysis of the Scleractinia (Cnidaria, Anthozoa) based on mitochondrial CO1 sequence data. PLoS ONE 5: e11490. 
Kitahara MV, Stolarski J, Cairns SD, Benzoni F, Stake JL, Miller DJ. 2012b. The first modern solitary Agariciidae (Anthozoa, Scleractinia) revealed by molecular and microstructural analysis. Invertebrate Systematics 26: 303-315.

Kitahara, MV, Fukami H, Benzoni F, Huang D. 2016. The new systematics of Scleractinia: integrating molecular and morphological evidence. In: Goffredo S, Dubinsky Z. (eds.), The Cnidaria, Past, Present and Future: The World of Medusa and Her Sisters. Springer Netherlands, Dordrecht.

Kitano YF, Benzoni F, Arrigoni R, Shirayama Y, Wallace CC, Fukami H. 2014. A phylogeny of the family Poritidae (Cnidaria, Scleractinia) based on molecular and morphological analyses. PLoS ONE 9: e98406.

Librado P, Rozas J. 2009. DnaSP v5: A software for comprehensive analysis of DNA polymorphism data. Bioinformatics 25: 1451-1452.

Matthai G. 1928. A monograph of the recent meandroid Astraeidae. Catalogue of Madreporarian Corals British $\mathrm{Mu}$ seum (Natural History) 7: 1-288.

Milne-Edwards M, Haime J. 1848. Recherches sur les polypiers; 4eme mémoire. Monographie des Astréides. Annales des Sciences Naturelles 10: 209-320.

Nylander JAA. 2004. MrModeltest v2. Uppsala: Evolutionary Biology Centre, Uppsala University.

Obura DO. 2012. The diversity and biogeography of Western Indian Ocean reef-building corals. PLOS ONE 7: e45013.

Pichon M, Benzoni F, Chaineu CH, Dutriex E. 2010. Field Guide to the hard corals of the southern coast of Yemen. Paris: Biotope Parthenope.

Pinzón JH, Sampayo E, Cox E, Chauka LJ, Chen CA, Voolstra CR, LaJeunnesse TC. 2013. Blind to morphology: genetics identifies several widespread ecologically common species and few endemics among Indo-Pacific cauliflower corals (Pocillopora, Scleractinia). Journal of Biogeography 40: 1595-1608.

Rambaut A, Drummond AJ. 2009. Tracer: MCMC Trace Analysis Tool. Version 1.5. Available via http://beast.bio.ed.ac.uk

Reijnen BT, McFadden CS, Hermanlimianto YT, van Ofwegen LP. 2014. A molecular and morphological exploration of the generic boundaries in the family Melithaeidae (Coelenterata: Octocorallia) and its taxonomic consequences. Molecular Phylogenetics and Evolution 70: 383-401.

Scheer G, Pillai CSG. 1983. Report on the stony corals from the Red Sea. Zoologica 133: 1-198.

Schmidt-Roach S, Miller KJ, Lundgren P, Andreakis N. 2014. With eyes wide open: a revision of species within and closely related to the Pocillopora damicornis species complex (Scleractinia; Pocilloporidae) using morphology and genetics. Zoology Journal of the Linnean Society 170: 1-33.

Stefani F, Benzoni F, Yang SY, Pichon M, Galli P, Chen CA. 2011. Comparison of morphological and genetic analyses reveals cryptic divergence and morphological plasticity in Stylophora (Cnidaria, Scleractinia). Coral Reefs 30: 10331049.

Stolarski J. 2003. 3-Dimensional micro- and nanostructural characteristics of the scleractinian corals skeleton: a biocalcification proxy. Acta Palaeontologica Polonica 48: $497-$ 530 .

Stolarski J, Roniewicz E. 2001. Towards a new synthesis of evolutionary relationships and classification of Scleractinia. Journal of Paleontology 75: 1090-1108.
Swofford DL. 2003. PAUP*. Phylogenetic Analysis Using Parsimony (*and other methods). Version 4. Sunderland: Sinauer Associates.

Takabayashi M, Carter DA, Loh WKT, Hoegh-Guldberg O. 1998. A coral-specific primer for PCR amplification of the internal transcribed spacer region in ribosomal DNA. Molecular Ecology 7: 925-931.

Terraneo TI, Berumen ML, Arrigoni R, Waheed Z, Bouwmeester J, Caragnano A, Stefani F, Benzoni F. 2014. Pachyseris inattesa sp. n. (Cnidaria, Anthozoa, Scleractinia): a new reef coral species from the Red Sea and its phylogenetic relationships. Zookeys 433: 1-30.

Vaughan TW, Wells JW. 1943. Revision of the Sub-orders, Families and Genera of the Scleractinia. Geological Society of America Special Papers 44: 1-363.

Veron JEN. 1985. New Scleractinia from Australian coral reefs. Records of the Western Australian Museum 12: 147183.

Veron JEN. 1992. Hermatypic corals of Japan. Australian Institute of Marine Science Monograph Series 9: 1-234.

Veron JEN. 1993. A biogeographic database of hermatypic corals. Australian Institute of Marine Science Monograph Series 10: 1-433.

Veron JEN. 1995. Corals in space and time: the biogeography and evolution of the Scleractinia. New York: Cornell University Press.

Veron JEN. 2000. Corals of the World. Townsville: Australian Institute of Marine Science.

Veron JEN, Marsh LM. 1988. Hermatypic corals of Western Australia: records and annotated species list. Records of the Western Australian Museum 29: 1-136.

Veron JEN, Pichon M. 1980. Scleractinia of Eastern Australia, III: Families Agariciidae, Siderastreidae, Fungiidae, Oculinidae, Merulinidae, Mussidae, Pectiniidae, Caryophylliidae, Dendrophylliidae. Australian Institute of Marine Science Monograph Series 4: 1-433.

Waheed Z, van Mil HGJ, Syed Hussein MA, Jumin R, Golam Ahad B, Hoeksema BW. 2015. Coral reefs at the northernmost tip of Borneo: an assessment of Scleractinian species richness patterns and benthic reef assemblages. PLOS ONE 10: e0146006.

Wallace CC, Done BJ, Muir PR. 2012. Revision and catalogue of worldwide staghorn corals Acropora and Isopora (Scleractinia: Acroporidae) in the Museum of Tropical Queensland. Memoirs of the Queensland Museum 57: 1-255.

Wallace CC, Chen CA, Fukami H, Muir PR. 2007. Recognition of separate genera within Acropora based on new morphological, reproductive and genetic evidence from Acropora togianensis, and elevation of the subgenus Isopora Studer, 1878 to genus (Scleractinia: Astrocoeniidae; Acroporidae). Coral Reefs 26: 231-239.

Wallace CC, Fellegara I, Muir PR, Harrison PL. 2009. The scleractinian corals of Moreton Bay, eastern Australia: high latitude, marginal assemblages with increasing species richness. Memoirs of the Queensland Museum - Nature 54: 1-118.

Wells JW. 1955. Recent and subfossil corals of Moreton Bay, Queensland. University of Queensland Papers Department of Geology 4: 1-18.

Wells JW. 1964. The recent solitary mussid scleractinian corals. Zoologische Mededelingen Leiden 39: 375-384. 
White TJ, Bruns T, Lee S, Taylor J. 1990. Amplification and direct sequencing of fungal ribosomal RNA genes for phylogenetics. Pp. 315-322 in: Innis MA, Gelfand DH, Sninsky JJ, White TJ., eds, PCR Protocols: A Guide to Methods and Application. San Diego: Academic Press.

Received: 17 August 2015

Revised and accepted: 25 January 2016

Published online: 30 September 2016

Editor: R.W.M. van Soest

\section{Online Supplementary Information}

S1. List of the material examined in this study from a molecular point of view. For each specimen we list code, identification, sampling locality, collector, and molecular markers used for the genetic analyses.

S2. Pairwise comparisons of genetic distance within and between clades of the family Lobophylliidae. Standard deviations listed on the upper right hand portions for each set of comparisons.

S3. ML tree based on mitochondrial COI dataset. Node values are ML SH-like support ( $>0.7)$.

S4. ML tree based on nuclear histone H3 dataset. Node values are ML SH-like support (>0.7).

S5. ML tree based on ITS region dataset. Node values are ML SH-like support (>0.7).

S6. Close-up of phylogenetic relationships among and within clades A and B from the phylogenetic tree reported in Fig. 3 and based on the combinaed COI, H3, and ITS region dataset.

S7. Coralla of Micromussa lordhowensis (previously Acanthastrea) examined in this study showing the range of intra-specific macromorphological variability of corallite shape, septal fusion and thickness. A) Holotype, MTQ G57483; B) AM 5098*; C) AM 5050*; D) AM AU055; E) AM AU008; F) AM 1642*** = specimens included in the phylogeny reconstruction in Fig. 3 (clade A).

S8. Intra-specific variability in situ of specimens of Micromussa lordhowensis (previously Acanthastrea) examined in this study. A) Two adjacent colonies with different colouration; B) A colony with brown and white rounded polyps and brown peristome; C) A colony with green and white rounded and irregular polyps and white peristome; D) A colony with brown and white rounded and irregular polyps and green peristome; E) A colony with green and white elongated polyps; F) Detail of a colony with grey and white irregular polyps and grey peristome; G) A colony with brown and white elongated and irregular polyps and red peristome; H) A colony with green and white irregularly shaped polyps and wide red peristome.

S9. Coralla of Micromussa multipunctata (previously Montastraea) examined in this study. A) RMNH Coel 24241; B) RMNH Coel 40077*; C) RMNH Coel 40078* (same colony as in Fig. S11C); D) RMNH Coel 40099*.* = specimens included in the phylogeny reconstruction in Fig. 3 (clade A).

S10. Intra-specific variability in situ of specimens of Micromussa multipunctata (previously Montastraea) examined in this study. A) A colony from Malaysia with "a chocolate-brown coenosarc colouration" described as the most typical by Hodgson (1985); B) A large colony from Malaysia with bright red and white polyps; C) Same colony as in Fig. 1C with orange retracted polyps; D) RMNH Coel 40078 from Malaysia, same colony as in Fig. S10C with bright red polyps. 
S11. Coralla of some of the specimens of Micromussa pacifica sp. nov. (referred to as Homophyllia cf. australis in text) examined in this study showing the intra-specific macromorphological variability of this species. Specimen code close to the images. All specimens are included in the phylogeny reconstruction in Fig. 3 (clade A).

S12. Coralla of some of the specimens of Homophyllia australis examined in this study showing the intra-specific macromorphological variability of this species. Specimen code close to the images. All specimens are included in the phylogeny reconstruction in Fig. 3 (clade B).

S13. Coralla of Homophyllia bowerbanki (previously Acanthastrea bowerbanki (B, D, F, H) and Acanthastrea hillae (A, C, E, G)) examined in this study showing the overlapping range of macromorphological variability between the two nominal species. A) Holotype of Acanthastrea hillae, UQF 179; B) Holotype of Acanthastrea bowerbanki, MNHN850; C) IRD HS3531*; D) IRD HS3285*; E) AM MH043*; F) IRD HS3446*; G) AM AU184 (left hand side corallum) growing adjacent to Homophyllia australis (single larger corallite on the right); H) AM AU249, same colony in Fig. 10H. White arrows point at the two columellae of the bicentric calice central to the corallum in both holotypes. Black arrows point at the prominent septal teeth of the first cycle of septa towards the columella.* $=$ specimens included in the phylogeny reconstruction in Fig. 3 (clade B).

S14. Intra-specific variability in situ of specimens of Homophyllia bowerbanki (previously Acanthastrea bowerbanki and Acanthastrea hillae) examined in this study. A) AM AU183, mottled green and red colony growing adjacent to Homophyllia australis (on the right); B) IRD HS3286, dark brown and white mottled colouration with a prominent central polyp; C) Orange and green colony at Noddy Island, Admiralty Group, Australia $\left(31^{\circ} 30.060^{\prime} \mathrm{S}\right.$; $159^{\circ} 3.823$ 'E , 16/12/2015); D) Brown and white coloured colony with a prominent central polyp at Lord Howe Island, Australia (31 30.695 'S; $\left.159^{\circ} 3.426^{\prime} \mathrm{E}, 16 / 12 / 2014\right)$; E) Beige and white colony with irregularly shaped polyps at Lord Howe Island, Australia (31³2.996'S; 159³.796'E, 17/12/2014); F) AM AU174, green, brown and white colony with large polyps roughly arranged around a central rounder one, Noddy Island, Admiralty Group, Australia (17/12/2015); G) A large colony with brown polyps and white peristome at Balls Pyramid, Lord Howe Island, Australia (31 ${ }^{\circ} 45.402$ 'S, $\left.159^{\circ} 14.253^{\prime} \mathrm{E}, 18 / 12 / 2014\right)$ (Picture by T.H. Sinclair-Taylor); H) AM AU249, large bright orange colony with a prominent central polyp (Picture by T.H. Sinclair-Taylor).

S15. Lectoype of Micromussa diminuta Veron, 2000 (A-B, D), holotypes of Goniopora somaliensis (C) and Acanthastrea minuta Moll \& Borel-Best, 1984 (E-F). A) MTQ G55851, whole specimen; B) Corallites showing the typical septal fusion and the pali of the genus Goniopora; C) USNM 21989, detail of the corallites; D) Longitudinal section of the corallites of the same specimen as in A and B showing the porous nature of septa and corallite walls resulting from the fusion of trabeculae and synapticulae typically observed in Goniopora; E) RMNH Coel 15275; F) Close up of a corallite showing the typical shape of costoseptal teeth of the genus Acanthastrea. White arrows point at the single process forming the columella which is surrounded by pali. 


\section{Appendix}

\section{Systematics}

Family Lobophylliidae Dai \& Horng, 2009

Genus Micromussa Veron, 2000

Type species: Acanthastrea amakusensis Veron, 1990

Revised diagnosis. Solitary or colonial with encrusting to submassive and massive coralla. Budding intracalicular and extracalicular. Corallites monomorphic. Corallite integration discrete. Monticules absent. Calice width small-medium, medium $(4-15 \mathrm{~mm})$ and large (> $15 \mathrm{~mm})$. Septa in $3-4$ cycles $(24-36$ septa) or more of four cycles ( $\geq 48$ septa). Free septa irregular. Between 6 and 11 septa per $5 \mathrm{~mm}$. Costosepta slightly unequal to unequal in relative thickness. Columellae trabecular and spongy, $>$ or $<1 / 4$ of calice width. At midcalice tooth base elliptical-parallel and tooth tip irregular. Septal teeth height medium $(0.3-$ $0.6 \mathrm{~mm})$ but can be high $(>0.6 \mathrm{~mm})$ in M. pacifica sp. nov. Tooth space medium $(0.3-1.0 \mathrm{~mm})$. Interarea smooth. Granules strong, pointed, scattered on septal face. Tooth shape equal between first and third order septa. Tooth size equal between midcalice and inner end in the first two cycles of septa.

Remarks. The main characters differentiating $M i$ cromussa from Homophyllia are the shape and distribution of granules (Table 1) which are strong, pointed, and scattered in the former genus and weak, rounded, uniformly distributed in the latter.

Species included.

Micromussa amakusensis (Veron, 1990) (Figs 1A, 2A, 7A-C, 14A, F)

Acanthastrea amakusensis Veron, 1990 p. 137, figs 42-44, 82

Micromussa amakusensis (Veron, 1990) Veron (2000) vol. 3, pp. 10-11, figs 1-4; Turak and Devantier 2011 p. 164 and figs therein

Acanthastrea lordhowensis Veron \& Pichon, 1982; Turak and Devantier 2011 p. 166 and figs therein

Type material. The holotype (MTQ G32485, Fig. 1A) from Amakusa Island, Japan is deposited at the MTQ.

Examined material. Japan - MTQ G32485 (holotype), Amakusa Island, 10m, 1988, coll. J.E.N. Veron; SMBL Cni-11051, Amakusa Island, 3.3m, 07/10/2009, coll. Y. Zayasu; SMBL Cni-11060, Amakusa Island, 3.9m, 07/10/2009, coll. Y. Zayasu; SMBL Cni-11049, Amakusa Island, 3.6m, 07/10/2009, coll. Y. Zayasu;
SMBL Cni-11055, 4.5m 07/10/2009, coll. Y. Zayasu; SMBL Cni-11046, Amakusa Island, 2.0m 07/10/2009, coll. Y. Zayasu.

Distribution. Japan and the Coral Triangle. Previous records of this species in the Indian Ocean (Veron, 2000) refer to Micromussa indiana sp. nov.

Micromussa lordhowensis (Veron \& Pichon, 1982) comb. nov. (Figs 1C, 2C, 14C, H, S5, S6)

Acanthastrea sp. Veron \& Pichon, 1980 pp. 264-266, figs 455-456

Acanthastrea lordhowensis Veron \& Pichon, 1982 p. 138; Veron (2000) vol. 3, pp. 14-15, figs 1-6; Wallace et al. (2009) figs 7D, 58A-F

Micromussa amakusensis (Veron, 1990) Wallace et al. (2009) figs 7F, 59A-B

Type material. The holotype G57483 (Figs 1C, S8A) from Lord Howe Island, Australia is deposited at the MTQ.

Examined material. Australia - (coll. A.H. Baird): AM 1596, AM 1597, Solitary Islands, Sandon Reef, 0.5m, 30/09/2012; AM 1598, Solitary Islands, Sandon Reef, 0.5m, 30/09/2012; AM 1642, Solitary Islands, Sandon Reef, 0.5m, 02/10/2012; AM 5019, AM 5023, AM 5038, Solitary Islands, Bubble Cave, 12m, 08/07/2014; AM 5050, Solitary Islands, Bubble Cave, 12m, 08/07/2014; AM 5063, AM 5079, AM 5085, AM 5098, AM 5099G, AM 5099R, Solitary Islands, Anemone Bay, 12m, 08/07/2014; AM MH042, Lord Howe Island, Admiralty Group, 20/03/2013, 14m, coll. M. Hoogenboom; MTQ (Moreton Bay collection, coll. C.C. Wallace, I. Fellegara, P. Muir): G56540, Moreton Bay, Peel Island, 1m, 01/12/2001; G6628, Moreton Bay; MTQ (AIMS monograph coral collection, coll. M. Pichon and J.E.N. Veron): G57483 (holotype), Lord Howe Island, 1m; G58513, Lord Howe Island; BM(NH).1983.9.212; (coll F. Benzoni): AM AU008, Mutton Bird Bay $\left(30^{\circ} 18.237^{\prime} \mathrm{S}\right.$; 153⒐041'E), 06/12/2014; AM AU009, Mutton Bird Bay $\left(30^{\circ} 18.237^{\prime} \mathrm{S} ; 153^{\circ} 9.041^{\prime} \mathrm{E}\right), 06 / 12 / 2014 ; \mathrm{AM}$ AU014, Minnie Waters pools $\left(29^{\circ} 46.732^{\prime}\right.$ S; $153^{\circ}$ 18.199'E), 07/12/2014; AM AU044, SW Solitary, 08/12/21014; AM AU048, SW Solitary, 08/12/21014; AM AU055, Split Island ( $30^{\circ} 14.494^{\prime} S$; $\left.153^{\circ} 10.780^{\prime} \mathrm{E}\right)$, 08/12/21014; AM AU060, Split Island $\left(30^{\circ} 14.494 ’\right.$; $153^{\circ} 10.780$ 'E), 08/12/21014; AM AU120, N Solitary Bubble (295 55.644'S153 23.359'E), 10/12/2014; AM 
AU121, N Solitary Bubble (2955.644'S; $153^{\circ}$ 23.359'E), 10/12/2014.

Distribution. According to Veron (2000) Western Australia and the coral triangle. Previous records of this species in the Indian Ocean (Veron, 2000) refer to Micromussa indiana sp. nov.

Micromussa multipunctata (Hodgson, 1985) comb. nov. (Figs 1D, 2D, 14D, I, S7, S8)

Montastrea multipunctata Hodgson, 1985, figs 1-8, 9; Veron (2000) vol. 3, p. 221, figs 4-7

Micromussa minuta (Moll \& Borel-Best, 1984) Veron (2000) in part, vol. 3, p. 8, skeleton picture

Type material. Four syntypes (UP C-783, UP C-786, UP C-787, UP C-788) from Tambuli Reef, Mactan Island, Cebu, Philippines are deposited at the UP.

Examined material. Malaysia, North Sabah RMNH (coll. B.W. Hoeksema): Coel. 40077, station TMP20, Banggi Outer NE Reef $\left(07^{\circ} 22.54^{\prime} \mathrm{N}\right.$, $\left.117^{\circ} 22.25^{\prime} \mathrm{E}\right), 8 \mathrm{~m}, 14 / 09 / 2012$; Coel. 40078, station TMP20, Banggi Outer NE Reef $\left(07^{\circ} 22.54^{\prime} \mathrm{N}\right.$, $\left.117^{\circ} 22.25^{\prime} \mathrm{E}\right), 9 \mathrm{~m}, 14 / 09 / 2012$; Coel. 40099, station TMP19, Outer Latoan Patch $\left(07^{\circ} 22.54^{\prime} \mathrm{N}\right.$, $\left.117^{\circ} 22.25^{\prime} \mathrm{E}\right), 8 \mathrm{~m}, 14 / 09 / 2012$; Philippines - RMNH Coel. 24241 Mactan Island, Cebu, 1-5m, 01/05/1981; UP P1L02161, Talim Point, Batangas, Philippines, 6.6m, 22/08/2009, coll. D. Huang.

Distribution. From the Coral Triangle to the northern central Pacific (Veron, 2000).

Micromussa indiana Benzoni \& Arrigoni sp. nov. (Figs 1B, 2B, 5, 6, 7D-F, 14B, G)

Micromussa amakusensis (Veron, 1990) Claereboudt (2006) pp. 226-227 and figures therein; Pichon et al. (2010) pp. 232-233, figs $1-4$

Type material. The holotype (MNHN IK-2012-14232, Figs 1B, 2B, 5A-B) from Al Mukallah, Yemen is deposited at MNHN.

Examined material. Yemen, Red Sea - UNIMIB (coll. F. Benzoni): KA099, Tiqfash Island, Kamaran

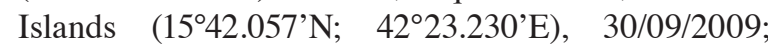
KA113, Tiqfash Island, Kamaran Islands (15² $2.033^{\prime} \mathrm{N}$; 42 $\left.{ }^{\circ} 23.144^{\prime} \mathrm{E}\right), 30 / 09 / 2009$; KA119, Tiqfash Island, Kamaran Islands $\left(15^{\circ} 42.033^{\prime} \mathrm{N}\right.$; $\left.42^{\circ} 23.144^{\prime} \mathrm{E}\right)$, 30/09/2009; Yemen, Gulf of Aden - MNHNIK-2012-14232, Al Mukallah (14³0.801'N; 49 $10.338^{\prime}$ E), 20/03/2007, coll. F. Benzoni and M. Pichon; UNIMIB (coll. F. Benzoni): AD069, Aden
(1245.267’N; 4454.983’E), 10/03/2009; BA072, Bir Ali (1359.180'N; 48¹5.692'E), 19/11/2008; BA117, Bir Ali (13 $55.648^{\prime} \mathrm{N}$; 48 $\left.23.234^{\prime} \mathrm{E}\right), 22 / 11 / 2008$; BU001, Burum $\left(14^{\circ} 18.480^{\prime} \mathrm{N} ; \quad 48^{\circ} 57.899^{\prime} \mathrm{E}\right)$, 22/03/2007; FP, Al Mukallah (14³0.801'N; 49 $\left.{ }^{\circ} 10.338^{\prime} \mathrm{E}\right), 20 / 03 / 2007$; MU183, Al Mukallah (14³0.801'N; 49¹0.338'E), 20/03/2008; MU184, Al

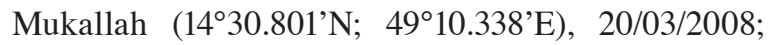
MU186, Al Mukallah (14³0.801'N; 49¹0.338'E), 20/03/2008; MU215, Al Mukallah (14³1.046’N; 49 $\left.10.285^{\prime} \mathrm{E}\right), 21 / 03 / 2008$; Yemen, Socotra Island EPA S C3695, 01/03/1999; UNIMIB SO071, Di Hamri (1240.518'N; 54²11.394'E), 14/03/2010, coll. F. Benzoni; MTQ G57461 Ras Bidou; Kenya - RMNH Coel. 17290 Watamu Marine National Reserve, Mayungu, 3m, 06/04/1983, coll. H. Moll.

Etymology. The name refers to the currently known geographic distribution of this species, restricted to the Indian Ocean.

Description. Colonial with encrusting coralla. Budding intracalicular and extracalicular. Corallites irregularly polygonal in outline. Calice width $5-10$ $\mathrm{mm}$, diameter variable between calices of the same corallum. Septa in $3-4$ cycles ( $24-36$ septa), those of the first two cycles (the second sometimes incomplete) reach the columella, those of the other cycles, often incomplete, are free. Costosepta are unequal in relative thickness (Fig. 5B). Columellae trabecular and spongy $<1 / 4$ of calice width (Fig. 5C). Septal teeth height medium $(0.3-0.6 \mathrm{~mm})$. Interarea smooth. Granules strong, pointed, scattered on septal face.

Holotype. The specimen is an irregularly shaped fragment of a colony, it measures $12 \times 8.5 \times 2 \mathrm{~cm}$ and has an encrusting growth form (Fig. 5A). The corallites are irregularly polygonal in outline and their largest diameter ranges from 0.5 tol cm (Figs 1B, 5B). Up to 4 cycles of septa are visible in the largest corallites, while only the first three are present in smaller corallites, sometimes the second and the third ones incomplete (Fig. 5B). Septa of the first 2 cycles reach the columella. Columellae are trabecular and measure from 1 to $2.5 \mathrm{~mm}$ in diameter. In vivo, the colony had a greenish colour with bright red peristome (Fig. 2B).

Remarks. Within the genus, this species is distinguished from M. amakusensis which has slightly larger corallites, 4 cycles of more regularly arranged septa the first 3 of which reach a larger columella (Fig. 7A) ( $>1 / 4$ of calice width) made of more numerous processes (Fig. 7A, C). Septal teeth are more regularly spaced along the septum in M. amakusensis (Fig. 7B) 
than in M. indiana (Fig. 7E). The latter has smaller corallites and less numerous septa than M.lordhowensis and is readily told apart from $M$. multipunctata which is plocoid, and from M. pacifica sp. nov. which has much larger and predominantly solitary coralla with more numerous septa (Table 1).

Colour. The peristome has a different colour from the rest of the polyp all the combinations of bright red, orange, brown, green, grey and white have been observed (Fig. 6).

Ecology. This species is found between 2 and $10 \mathrm{~m}$ depth in protected environments where it grows on hard substrates often in proximity of pockets of sediment. The thin colonies are often infested by polychaetes, boring bivalves, cirripeds and gall crabs (e.g. the holotype in Fig. 5A).

Distribution. Southern Red Sea, North-western Gulf of Aden, Socotra Island, Oman, Kenya.

\section{Micromussa pacifica Benzoni \& Arrigoni sp. nov.} (Figs 1E, 2E, 8, 9, 12D-F, 14E, J, S9)

Scolymia australis Veron \& Pichon 1980 in part, figs 425-426, 428-429; Veron, 2000 in part, vol. 3 pp. 7071 , figs 1,6

Type material. The holotype (MNHN IK-2012-16043, Figs 8F, 9D, S11) and a paratype (MNHN IK-201216044, Fig. 8G-I), both from Taravai Island, Gambier Islands, French Polynesia are deposited at MNHN.

Examined material. Australia - RMNH Coel. 16306, Erith Island, Murray Pass, May 1974; AM AU133, Lord Howe Island (31 31.076 'S; 159³.929'E), 14/12/2014, coll. F. Benzoni; AM AU141, Lord Howe Island (31 $33.224^{\prime}$ 'S; $\left.159^{\circ} 4.480^{\prime} \mathrm{E}\right)$, coll. F. Benzoni, 15/12/2014; New Caledonia - MNHN IK-2012-16045, Loyalty Islands, Ouvéa Island, Bagaat (20³7.448'S; 166¹6.252'E), 21/02/14, coll. F. Benzoni, BIBELOT Expedition; MNHN IK-2012-16046, Loyalty Islands, Ouvéa Island (20²5.426'S; $\left.166^{\circ} 29.098^{\prime} \mathrm{E}\right), 22 / 02 / 14$, coll. F. Benzoni, BIBELOT Expedition; IRD HS3202, Cap Begat (21 $21.242^{\prime} S$; 16552.142'E), 19/04/2012, coll. F. Benzoni; IRD (BIBELOT Expedition, Loyalty Islands, coll. F. Benzoni): HS3327, Loyalty Islands, Maré Island, south of Cap Machan (21 24,967'S; 167²9,152’E), 15/02/14; HS3359, Maré Island, Tadine Bay $\left(21^{\circ} 35.283^{\prime} S ; 1^{\circ} 7^{\circ} 51.258^{\prime} \mathrm{E}\right), 15 / 02 / 14$; HS3471, Lifou Island, Cap Ainé Martin (206.857'S; $167^{\circ} 02.272$ 'E), 20/02/14; HS3527, Astrolabe Reef, Oues Reef (1952.194'S; 165³3.375'E), 24/02/2014; HS3528, Astrolabe Reef, Oues Reef (1952.194'S; $\left.165^{\circ} 33.375^{\prime} E\right), 24 / 02 / 2014$; French Polynesia, Gam- bier Islands - MNHN IK-2012-14249, coll. M. Seurat, 15/09/1902; MNHN (Tara Oceans Expedition, coll. F. Benzoni): IK-2012-16043, Taravai Island (2308.72'S; $\left.135^{\circ} 03.09^{\prime} \mathrm{W}\right), 08 / 07 / 2011$; IK-2012-16044, Taravai Island (2308.72'S; $\left.135^{\circ} 03.09^{\prime} \mathrm{W}\right), 08 / 07 / 2011$; UNIMIB (Tara Oceans Expedition, coll. F. Benzoni): GA130, NE Lagoon pinnacles (230.12’S; $\left.134^{\circ} 55.83^{\prime} \mathrm{W}\right)$, 05/07/2011; GA150, Taravai Island $\left(23^{\circ} 08.72^{\prime} \mathrm{S}\right.$; 13503.09'W), 08/07/2011; GA186, Tekava Island (23⒑13'S; $\left.134^{\circ} 51.51^{\prime} W\right), 10 / 07 / 11$; French Polynesia, Austral Islands - MTQ (International collection): G64026, Rapa Island, Tarakoi; G64051, Rapa Island, Baie Aurei; G64052, Rapa Island, Baie Aurei.

Etymology. The name refers to the geographic distribution of this species, restricted to the central and western Pacific Ocean.

Description. Solitary (Fig. 8A-B) to polystomatous (Fig. 8C) or forming coralla up to 3 corallites (Fig. 8D-I). Budding intracalicular (Fig. 8C) and extracalicular (Fig. 8F-I). Corallites round in outline. Calice width $15-25 \mathrm{~mm}$. Septa in $4-5$ cycles ( $\geq 48$ septa), those of the first three cycles reach the columella, those of the fourth fuse with those of the third just before reaching the columella, and those of the fifth or more are free and often incomplete (Fig. 8D-E). Costosepta slightly unequal to unequal in relative thickness (Fig. 8D). Columellae trabecular and spongy, < $1 / 4$ of calice width (Fig. 8D-F). Septal teeth height medium $(0.3-0.6 \mathrm{~mm})$ but can be high $(>0.6 \mathrm{~mm})$ in some specimens. Tooth space medium (0.3-1 mm). Interarea smooth. Granules strong, pointed, scattered on septal face.

Holotype. The specimen includes two corallites growing on a slab of dead tabular Acropora (Figs 8F, S9). The largest corallite is rounded in shape and it measures $2.3 \mathrm{~cm}$ in diameter, the smaller one, budding from the former extracalicularly, is oval in shape and is $0.9 \mathrm{~cm}$ in diameter (shown by the arrow in Fig. 8F). The living colony included a third even smaller corallite (Fig. 9D) which was sampled for molecular analyses. The largest corallite presents 5 cycles of septa, the fourth one incomplete. Septa of the first 3 cycles reach the columella which is trabecular and $3.5 \mathrm{~mm}$ in diameter. In vivo, the colony had bright red peristome (Fig. 9D).

Remarks. Within the genus, this species is readily distinguished from all the others by the size of corallites and number of corallites and septa. The macromorphology and the in situ appearance of this species are closer to those of $H$. australis, with similar corallum shape 
and number of septa, than to any other congener within Micromussa. However, H. australis has overall larger corallites and wider septal tooth spacing. Septal teeth are between 2 to $4 \mathrm{~mm}$ apart in $H$. australis (Fig. 12B-C) and between 0.5 and $2.5 \mathrm{~mm}$ apart in in $M$. pacifica (Fig. 12E-F). In fact, the character which perhaps is most useful for telling the two species apart is the increase in tooth size between midcalice and inner end in the first two cycles of septa observed in H. australis (arrows in Fig. 10B-C) but not in the new species. In particular, the tallest septa on primary septa in H. australis can reach up to $4 \mathrm{~mm}$ while (e.g. Fig. 10D) while they reach an observed maximum of $2.5 \mathrm{~mm}$ in M. pacifica (e.g. Fig. 8E).

Colour. The peristome has a different colour from the rest of the polyp all the combinations of bright red, orange, brown, green, grey and white have been observed (Fig. 9). In situ, this species and H. australis can co-occur (for example, in New Caledonia and Australia) and are found in the same habitats. They can be told apart by the more uniform within polyp colouration in the former (Fig. 9), and the more frequent and abundant presence of white areas in the peristome and, especially, over the septa in the latter (Fig. 11).

Ecology. This species is found between 10 and $40 \mathrm{~m}$ depth in protected environments with high sedimentation as well as in the deeper parts of outer reef slopes. The holotype and other specimens were growing on hard substrate coming from coral rubble consisting of fragments of dead tabular Acropora (Fig. S11).

Distribution. French Polynesia (Gambier and Austral Islands), New Caledonia (Grand Terre and Loyalty Islands), and eastern Australia.

Remarks. Two specimens of this species were sampled in the Gambier Islands in 1902 by M. Seurat, then director of the Biological Reseach Laboratory in Rikitea (1902-1904), and deposited in the MNHN general collection (IK-2012-14249). They had been previously identified as Mussa costata Dana, 1846 and Scolymia ? by different authors.

Genus Homophyllia Brüggemann, 1877

Type species: Homophyllia australis (Milne Edwards \& Haime, 1849)

Revised diagnosis. Solitary or colonial with encrusting to submassive and massive coralla. Budding mainly intracalicular, extracalicular budding is also observed. Corallites monomorphic although central larger and rounder corallites are often observed in colonial coralla. Corallite integration discrete. Monticules absent.
Calice width large ( $>15 \mathrm{~mm})$. Septa in more than four cycles ( $\geq 48$ septa). Free septa irregular. Between 6 and 11 septa per $5 \mathrm{~mm}$. Costosepta unequal in relative thickness. Columellae trabecular and spongy, $<1 / 4$ of calice width. At midcalice tooth base elliptical-parallel and tooth tip irregular. Septal teeth height high (> $0.6 \mathrm{~mm})$. Tooth space wide (>1 mm). Interarea smooth. Granules weak, rounded, uniformly distributed on septal face. Tooth shape equal between first and third order septa. Tooth size increases between midcalice and inner end in the first two cycles of septa.

Remarks. The main characters differentiating Homophyllia from Micromussa are the shape and distribution of granules (Table 1) which are weak, rounded, uniformly distributed in the former genus and strong, pointed, and scattered in the latter.

Species included.

Homophyllia australis (Milne Edwards \& Haime, 1849) (Figs 1F, 2F, 10, 11, 122A-C, 14K, P, S10)

Caryophyllia australis Milne Edwards \& Haime, 1849 p. 320 , pl. 8 fig. 2

Scolymia cf. vitiensis (Bruggemann, 1877) Veron \& Pichon (1980) fig. 412

Scolymia australis (Milne Edwards \& Haime, 1849) Veron \& Pichon (1980) in part, figs 427, 429-431; Veron (2000) in part vol. 3, pp. 70-71, figs 2-5

Scolymia (= Homophyllia) australis (Milne Edwards $\&$ Haime, 1849) Budd \& Stolarski (2009) figs 2K, 4K, $5 \mathrm{~A}, 6 \mathrm{~K}, 7 \mathrm{E}, 7 \mathrm{~K}, 11 \mathrm{H}$

Type material. Two syntypes NHMUK 1840.11.30.77 and NHMUK 1840.11.30.79) from South Australia. Original designation Brüggemann, 1877: 310.

Examined material. Australia - AM 4631, Lord Howe Island, 19/03/2013, 1m, coll. A.H. Baird; AM AU176, Noddy Island, Admiralty Group (3130.060'S; 159³.823'E), 16/12/2014, coll. F. Benzoni; AM AU177, Noddy Island, Admiralty Group (31³0.060'S; 159³.823'E), 16/12/2014, coll. F. Benzoni; AM AU178 Noddy Island, Admiralty Group (3130.060'S; $159^{\circ} 3.823^{\prime}$ E), 16/12/2014, coll. F. Benzoni; New Caledonia - MNHN IK-2012-14248, coll. J.P. Chevalier; IRD HS3311, coll. F. Benzoni; IRD (BIBELOT Expedition, Loyalty Islands, coll. F. Benzoni): HS3441, Luengoni, Lifou Island (2101.798'S; $\left.167^{\circ} 24.710^{\prime} \mathrm{E}\right)$, 18/02/2014; HS3447, Doking Bay, Lifou Island (2042.813'S; $\left.167^{\circ} 09.284^{\prime} \mathrm{E}\right), 19 / 02 / 2014 ;$ HS3469, Cap Ainé Martin, Lifou Island (2046.857'S; $167^{\circ} 02.272$ 'E), 20/02/2014; HS3470, Cap Ainé Mar-

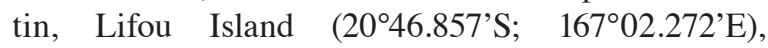


20/02/2014; HS3524, Astrolabe Reef (1952.194'S; $\left.165^{\circ} 33.375^{\prime} \mathrm{E}\right), 24 / 02 / 2014$; HS3525, Astrolabe Reef (1952.194'S; $\left.165^{\circ} 33.375^{\prime} \mathrm{E}\right), 24 / 02 / 2014$; HS3526, Astrolabe Reef (1952.194'S; 165³3.375'E), 24/02/2014; IRD (BIBELOT Expedition, Grande Terre, coll. F. Benzoni): HS3544, Port Bouquet, Nenii Reef (2140.193'S; $\left.166^{\circ} 24.373^{\prime} \mathrm{E}\right), 25 / 02 / 2014 ;$ HS3545, Port Bouquet, Nenii Reef ( $21^{\circ} 40.193$ 'S; $166^{\circ} 24.373$ 'E), 25/02/2014; IRD (CORALCAL5 Expedition, Ile des Pins, coll. F. Benzoni): HS3591, Ilôt Ndié (22³1.560'S; 167¹2.151'E), 29/09/2015; IRD (CHEST Expedition, Chesterfields and Bellona, coll. F. Benzoni): HS4177, Ilot Loop (1953'.763'S; 158²7.996'E), 19/11/2015.

Distribution. Western Pacific, North-west to Southwest Australia, New Caledonia.

Remarks. Veron and Pichon (1980) record this species also "from the western Pacific east to the Marshall Islands and Fiji". We did not examine material from this region and cannot ascertain if the mentioned record actually refers to this species or to Micromussa pacifica sp. nov., which has likely been confused with it in the literature so far (Veron and Pichon, 1980).

Homophyllia bowerbanki (Milne Edwards \& Haime, 1857) comb. nov. (Figs 1G-H, 2G-H, 14L-M, Q-R, S13, S14)

Acanthastrea bowerbanki Milne Edwards \& Haime, 1857 p. 503, pl. D6, fig. 1; Veron (2000) vol. 3 p. 26, figs 1-3; Wallace et al. (2009) fig. 56

Acanthastrea cf. bowerbanki (Milne Edwards \& Haime, 1857) Veron \& Pichon (1980) figs 449-454

Acanthastrea hillae Wells, 1955 pl. 2, figs 2- 3; Chevalier (1975) pl. XXX, fig. 2; Veron \& Pichon (1980) figs 440-441, 443, 445-447; Veron (2000) vol. 3 pp. 2829, figs 1-5; not Claereboudt (2006) pp. 214-215 and figures therein; not Dai and Horng (2009) p. 80 and figures therein; Wallace et al. (2009) fig. 57

Acanthastrea cf. hillae Wells, 1955 Chevalier (1975) pl. XXX, fig. 4 (Holotype of A. bowerbanki)

Type material. The holotype (scle850, Fig. S13A) from Australia is deposited at the MNHN..

Examined material. Australia - AM 4629, Lord Howe Island, 1m, 19/03/2013, coll. A.H. Baird; AM MH019, Lord Howe Island, Admiralty Group, 19/03/2013, 14m, coll. M. Hoogenboom; AM MH043, Lord Howe Island, Admiralty Group, 20/03/2013, 14m, coll. M. Hoogenboom; AM MH046, Lord Howe Island, Admiralty Group, 14m, 20/03/2013, coll. M. Hoogenboom; MTQ (Moreton Bay collection, coll. C.C. Wallace, I. Fellegara, P. Muir): G58484, Strad- broke Island, 8m, 22/05/2005; G58486, Goat Island, 2m, 23/05/2005; G56536, Moreton Bay, Peel Island, 01/02/2002; G55343, Moreton Bay, Goat Island, 2m, 23/02/2005; MTQ (AIMS monograph coral collection, Coll. M. Pichon and J.E.N. Veron): G43111, Byron Bay, 1m; G43110, Dewar Island, 10m; G58034, Lord Howe Island, 20m; G58033, Lord Howe Island, 20m; G58032, Lord Howe Island, 1m; G58035, Heron Island, 10m; G58036, Lord Howe Island, 1m; University of Miyazaki AuB167, Moreton Bay, 20/07/2007, 7m, coll. H. Fukami; New Caledonia - IRD (CORALCAL4 Expedition, coll. F. Benzoni): ): HS3066, Yandé Island (2003.620'S; 163²7.312'E), 12/04/2012; HS3163, Moneo (21 $\left.03.354^{\prime} S ; \quad 165^{\circ} 35.297^{\prime} \mathrm{E}\right), \quad 18 / 04 / 2012$;

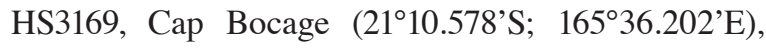

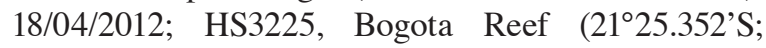
$\left.165^{\circ} 00.207^{\prime} \mathrm{E}\right), 21 / 04 / 2012$; HS3285, Canal Woodin (22²3.800'S; 166 46.440’E), 25/04/2012; HS3286, Canal Woodin $\left(22^{\circ} 23.800^{\prime} \mathrm{S} ; \quad 166^{\circ} 46.440^{\prime} \mathrm{E}\right)$, 25/04/2012; HS3287, Canal Woodin (22 $23.800^{\prime} S$; 166 46.440 'E), 25/04/2012; HS3288, Canal Woodin

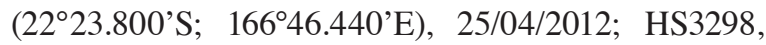
Recif Kué (22³8.638'S; 166³6.292'E), 26/04/2012; IRD (BIBELOT Expedition, Loyalty Islands, coll. F. Benzoni): HS3438, Luengoni (2101.798'S; $167^{\circ} 24.710$ 'E), 18/02/2014; HS3501, Beautemps-Beaupré, Motu One (20²2.141'S; 166 07.115'E), 23/02/2014; HS3531, Nenii Reef (2140.193'S; $\left.166^{\circ} 24.373^{\prime} \mathrm{E}\right), 25 / 02 / 2014$; HS3525, Astrolabe Reef (1952.194'S; 165³3.375'E), 24/02/2014; HS3526, Astrolabe Reef (1952.194'S; 165³3.375'E), 24/02/2014; HS3446, Cap Escarpé, Lifou Island (2041.039'S; 167¹3.596'E), 19/02/2014; HS3489, Ouvéa Island (20²6.663'S; $\left.\quad 166^{\circ} 24.016^{\prime} \mathrm{E}\right), \quad 22 / 02 / 2014 ; \quad$ IRD (CHEST Expedition, Chesterfields and Bellona, coll. F. Benzoni): HS3983, Ilot Reynard (19¹2.788'; $158^{\circ} 56.806^{\prime}$ E), 10/11/2015. Japan - SMBL Cni-10422, Nishidomari, Kochi Prefecture, 3.0m, 13/01/2006, coll. H. Fukami; SMBL Cni-10113, Yokonami, Kochi Prefecture, 8.4m, 22/10/2008, coll.Y. Zayasu; SSH12, Shirahama, Wakayama Prefecture, 3.0m, 05/2005 coll. H. Fukami.

Distribution. Western Pacific with high latitudinal distribution in the north and in the south, North and Eastern Australia, New Caledonia. Previous records of A. hillae in the Indian Ocean (Veron, 2000) refer to Acanthastrea hemprichii.

Genus Australophyllia Benzoni \& Arrigoni gen. nov. Type species: Australophyllia wilsoni (Veron, 1985) comb. nov. 
Etymology. The name refers to the peculiar and narrow geographic distribution of this genus.

Diagnosis. Colonial with submassive to massive coralla. Budding intracalicular and extracalicular. Corallites monomorphic. Corallite uniserial and discrete. Monticules present. Calice width medium (4 $15 \mathrm{~mm}$ ). Septa in more than four cycles ( $\geq 48$ septa). Free septa irregular. Between 6 and11 septa per $5 \mathrm{~mm}$. Costosepta unequal in relative thickness. Adjacent corallite centers discontinuous with lamellar linkage. Columellae trabecular and spongy, $<1 / 4$ of calice width in series although it can be larger in monocentric corallites. At midcalice tooth base elliptical-parallel and tooth tip irregular. Septal teeth height medium $(0.3-0.6 \mathrm{~mm})$. Tooth space medium $(0.3-1 \mathrm{~mm})$. Interarea smooth. Granules weak, rounded, scattered on septal face. Tooth shape equal between first and third order septa. Tooth size equal between midcalice and inner end in the first two cycles of septa.

Remarks. The main characters differentiating Australophyllia from the other genera in this study are the uniserial corallites, which are discrete in all the other examined taxa, the discontinuous corallite centre linkage as opposed to the absence of linkage in the other taxa. Moreover, in Australophyllia and the granules on septal sides are weak, rounded, scattered while they are strong, pointed, and scattered in Micromussa, weak, rounded, uniformly distributed in Homophyllia, and weak, rounded, enveloped by thickening deposits in Acanthastrea (Table 1).

Species included (monotypic genus).

Australophyllia wilsoni (Veron, 1985) comb. nov. (Figs 1I, 2I, 13, 14N-S)

Symphyllia wilsoni (Veron, 1985) pp. 169-170, figs 1822; Veron, 2000, vol. 3, p. 53, figs 2-4

Type material. The holotype (Z910) from Rat Island, Houtman Abrolhos Islands, Western Australia is deposited at the WAM. Two paratypes (Z911, Z912) are deposited at the WAM.

Examined material. Western Australia - (coll. D.P. Thomson): AM WIL1, Hall Bank, 09/04/2013, 9m; AM WIL2, Hall Bank, 09/04/2013, 9m; AM WIL3, Hall Bank, 09/04/2013, 9m; AM WIL4, AM WIL5; RMNH Coel. 22399, West Australia, Abrolhos
Islands, 2m, 03/04/1976; WAM 168-84 (holotype), Rat Island, Houtman Abrolhos Islands, Western Australia, 8m, 1983, coll. J.E.N. Veron; paratype (WAM 169-84), Port Denison, Western Australia, 9m, 1982, J.E.N. Veron; paratype (WAM 170-84), Port Denison, Western Australia, 12m, 1982, coll. J.E.N. Veron.

Distribution. This species is restricted to Southwestern Australia and thrives in temperate conditions.

Genus Acanthastrea Milne Edwards \& Haime, 1848 Type species: Astraea echinata (Dana, 1846)

Species included.

Acanthastrea minuta Moll \& Borel-Best, 1984 (Fig. S15E, F)

Acanthastrea minuta Moll \& Borel-Best, 1984 p. 53, fig. 12

Type material. The holotype (RMNH 15275, Fig. S13E, F) from north Bone Tambung, Spermonde Archipelago, South Sulawesi, Indonesia is deposited at the RMNH.

Family Poritidae Gray, 1842

Genus Goniopora de Blainville, 1830

Type species: Goniopora pedunculata Quoy \& Gaimard, 1833

Species included.

Goniopora diminuta (Veron, 2000) (Fig. S15A, B, D) Micromussa diminuta Veron, 2000 p. 9, figs 1-4; Veron, 2002 p. 126, figs 235-237; ICZN, 2011, p. 164

Type material. The lectotype (MTQ G55851, Fig. S15A, B, D) from southern Sri Lanka is deposited at the MTQ. This species was described in Veron (2000) without designating type material and type locality, rendering it as nomen nudum. Subsequently, it was redescribed in Veron (2002) with the designation of a 'holotype' (MTQ G55851). Following ICZN (2011: 164), the Veron (2000) publication was validated as an available taxonomic work. The species named in Veron (2000) is therefore valid, but the type specimen designated in Veron (2002) is not (Wallace et al., 2012). Therefore this specimen is herein regarded as lectotype. 